\title{
Analyzing pathways from childhood maltreatment to internalizing symptoms and disorders in children and adolescents (AMIS): a study protocol
}

Lars O. White ${ }^{1 *}$, Annette M. Klein ${ }^{1}$, Clemens Kirschbaum², Maria Kurz-Adam³, Manfred Uhr ${ }^{5}$, Bertram Müller-Myhsok ${ }^{5,6,7}$, Katrin Hoffmann ${ }^{4}$, Susan Sierau', Andrea Michel', Tobias Stalder ${ }^{2}$, Jenny Horlich ${ }^{4}$, Jan Keil ${ }^{1}$, Anna Andreas ${ }^{1}$, Leonhard Resch ${ }^{1}$, Martin J. Binser ${ }^{3}$, Anna Costa ${ }^{3}$, Elena Giourges ${ }^{3}$, Eva Neudecker ${ }^{3}$, Christiane Wolf ${ }^{5}$, Sandra Scheuer, ${ }^{5}$ Marcus ssing $^{5}$ and Kai von Klitzing ${ }^{1}$

\begin{abstract}
Background: Effective interventions for maltreated children are impeded by gaps in our knowledge of the etiopathogenic mechanisms leading from maltreatment to mental disorders. Although some studies have already identified individual risk factors, there is a lack of large-scale multilevel research on how psychosocial, neurobiological, and genetic factors act in concert to modulate risk of internalizing psychopathology in childhood following maltreatment. To help close this gap, we aim to delineate gender-specific pathways from maltreatment to psychological disorder/resilience. To this end, we examine the interplay of specific maltreatment characteristics and psychological, endocrine, metabolomic, and (epi-)genomic stress response patterns as well as cognitive-emotional/social processes as determinants of developmental outcome. Specifically, we will explore endocrine, metabolomic, and epigenetic mechanisms leading from maltreatment to a higher risk of depression and anxiety disorders.

Methods/design: Four large samples amounting to a total of $\mathrm{N}=920$ children aged 4-16 years will be assessed: Two cohorts with prior internalizing psychopathology and controls will be checked for maltreatment and two cohorts with substantiated maltreatment will be checked for internalizing (and externalizing) psychopathology. We will apply a multi-source (interview, questionnaires, official records), multi-informant strategy (parents, children, teachers) to assess maltreatment characteristics (e.g., subtypes, developmental timing, chronicity) and psychopathological symptoms, supplemented with multiple measurements of risk and protective factors and cutting-edge laboratory analyses of endocrine, steroid metabolomic and epigenetic factors. As previous assessments in the two largest samples are already available, longitudinal data will be generated within the three year study period.
\end{abstract}

Discussion: Our results will lay the empirical foundation for (a) detection of early biopsychosocial markers, (b) development of screening measures, and (c) multisystem-oriented interventions in the wake of maltreatment.

Keywords: Maltreatment, Developmental psychopathology, Internalizing disorders, Developmental pathways, Neuroendocrine functioning, HPA axis, Gene-environment interaction, Cognitive-emotional strategies

\footnotetext{
* Correspondence: white@medizin.uni-leipzig.de

'Department of Child and Adolescent Psychiatry, Psychotherapy and

Psychosomatics, University of Leipzig, Leipzig, Germany

Full list of author information is available at the end of the article
} 


\section{Background}

Over $10 \%$ of children in western societies experience maltreatment [1-8]. Of the many health risks exhibited by individuals with a history of childhood maltreatment [9-13], one of the most consistent is a marked rise in risk for emotional and internalizing symptoms and disorders (e.g. Posttraumatic Stress Disorder; PTSD; Major Depressive Disorder; MDD; Anxiety Disorders) [14-20]. Thus, Scott et al. [17] found that abuse or neglect reported to child protection services (CPS) amplifies risk 5 to 10-fold for PTSD, 2 to 2.5-fold for mood disorders, and 2.5 to 3 -fold for anxiety disorders in adulthood. Nevertheless, maltreated children are a heterogeneous group and some develop alternate conditions, whereas others do not develop poor mental health at all ("multifinality") [21]. Importantly, we know very little about such multifinality or its origins, especially in childhood and adolescence $[16,22]$. The research project "Analyzing pathways from childhood maltreatment to internalizing symptoms and disorders in children and adolescents" (AMIS) seeks to shed light on the heterogeneity in response to trauma by assessing endocrine, metabolomic, and genomic stress response patterns to maltreatment alongside specific maltreatment characteristics, cognitiveemotional/social factors and psychopathological outcome in childhood.

\section{Theoretical background of our proposal}

Aiming to illuminate multifinality following maltreatment, AMIS is rooted in theories on differential susceptibility and biological sensitivity to context [23], which claim that individuals differ systematically in their sensitivity to environmental inputs. Based on Bronfenbrenner's [24] famous dictum that human development is a product of the exchanges between the individual and his/her environment, we assume that environmental influences (e.g., maltreatment) on developmental outcomes are modulated by genetic and neurobiological susceptibility to the environment [25], with gender potentially serving as a key moderator [26]. We seek to describe divergent developmental response profiles upon experiences of maltreatment by identifying different developmental pathways and outcomes. We firmly believe that a better understanding of multifinality soon after childhood maltreatment - which is the time when children often present to the Child Protective Services (CPS) - may benefit the development of effective individually tailored interventions.

We focus on the following putative key research areas (A. - E.) in AMIS to gain a more comprehensive understanding of developmental outcomes after maltreatment:

\section{A. Pattern of childhood maltreatment}

A well-documented source of heterogeneity in responses to maltreatment is the specific form and pattern of abuse and neglect a child experiences (e.g. subtype, severity, perpetrator, frequency, chronicity, and onset). For example, especially physical abuse which is chronic and neglect with early onset, predict internalizing and emotional symptoms in childhood and adolescence [16, 22, 27-30], giving rise to greater short- and long-term risk of internalizing problems $[16,28]$. Moreover, two studies by Kaplow and colleagues [31, 32] document that substantiated maltreatment (neglect, sexual and physical abuse) occurring prior to age 5 predicts greater anxiety and depressive symptoms in adulthood than maltreatment at later stages. Thus, beyond the dichotomous question of whether maltreatment took place or not, it is crucial to determine precisely which subtype(s) occurred during which periods of life, who exposed the child to maltreatment and at what frequency. Importantly, exact chronicling of patterns of childhood adversity and maltreatment is a precondition for accurate estimation of the role of genetic, neurobiological and psychological factors in determining developmental outcome.

\section{B. Genetic factors}

Human behavior and molecular genetic data suggest that genetic makeup acts as a crucial determinant of developmental outcome. In keeping with estimates of the heritability of adult depression [33], twin-studies estimate that genetic factors explain up to 40-50\% of the risk for emotional disorders in childhood and adolescence [34-40]. Candidate gene studies have implicated several depression genes thought to be involved in central neurotransmission [41-45] (e.g., SLC6A4, TPH2, GRIK3, and P2RX7), neurotrophic factors [46, 47] (e.g., BDNF and DISC1) and stress response regulation [48-50] (e.g., ACE and NR3C1). However, with a few notable exceptions [51], the role of these genes have not been confirmed via replication or meta-analysis and in a recent mega-analysis no single-nucleotide polymorphism crossed the boundary for genome-wide significance [52].

Accordingly, scholars contend that while genetic factors are important, they do not operate in isolation, but rather determine resilience/vulnerability jointly with a number of other variables, including environmental characteristics [53]. A series of landmark studies of gene-environment interaction $(\mathrm{GxE})$ helped to nurture a growing appreciation that specific genetic variants confer heightened susceptibility to psychopathology, but merely if individuals also experience environmental adversity [54-57]. Yet, despite these promising early results for single genotypes, many more genetic or environmental factors are likely involved in moderating short or long-term responses to stressful life events $[57,58]$, possibly accounting for failures to confirm these early findings in recent meta-analyses [59, 60]. 
These developments have prompted researchers to broaden their focus to include groups of genes known to be involved in the neurobiological stress response systems, such as the hypothalamic-pituitary-adrenocortical (HPA) axis. Thus, several labs have now observed GxE for variants of the CRHR1 gene, encoding the main receptor for the stimulant effects of the hypothalamic neuropeptide CRH on the endocrine stress response system [61-64]. Findings in adults also converge on FKBP5, which expresses an important modulator of the glucocorticoid receptor (NR3C1) involved in the regulatory feedback loop of the HPA axis. Specifically, a particular variant of this gene contributes to both responses to acute standardized stress [65] as well as development and relapse rate of internalizing disorders [66, 67]. Importantly, recent work from one of our labs indicates that a specific susceptibility genotype of FKBP5 confers elevated vulnerability to depression in young adults exposed to earlier critical life events while protective effects ensue for those with few or no such life events [68]. These data now clearly mandate research extending these patterns to childhood maltreatment and developmental samples.

\section{Endocrine stress response}

Over the past three decades evidence has accumulated that childhood maltreatment and adversity may exert marked and persistent influence on HPA axis activity [69-72]. These changes, in turn, constitute a risk factor for the development of internalizing and externalizing disorders in childhood and adulthood with genderspecific pathways [26, 71, 73-79]. Ample data from our labs and others implicate altered cortisol secretory activity as a correlate of childhood maltreatment, irrespective of whether cortisol levels were assessed during infancy [80], childhood [69, 81-83], adolescence [84] or adulthood [73, 85-88]. Interestingly, while aberrant cortisol secretory patterns have been repeatedly documented in maltreated subjects, some variability in the direction of reported findings has emerged [71, 89]. For example, whereas elevated cortisol concentrations were found in 24-h urinary as well as in morning salivary samples of maltreated children [69, 84], maltreated children also have also been found to exhibit attenuated morning salivary cortisol concentrations [83].

These inconsistencies may partly originate from lack of research integrating HPA axis findings with data on genotypes, epigenetic programming as well as psychosocial processes. In addition, variations in maltreatment experiences themselves may account for some of these inconsistencies. Research from our group [88], for example, shows that in a sample of 623 international adult adoptees, those with early experience of severe neglect exhibit lower morning cortisol levels (hypocortisolism) and a flatter cortisol decline across the day vs. nonabused adoptees. Conversely, neglected adoptees who also experienced moderate physical abuse displayed higher morning cortisol and a steeper diurnal decline. Other studies also report fluctuations in cortisol patterns as a function of maltreatment subtype [21].

Moreover, divergent, partly gender-specific, developmental pathways and mental disorders following trauma may give rise to differential cortisol patterns. For example, hypocortisolism and blunted cortisol responsivity typifies individuals with PTSD and/or exposed to traumatic life events [76, 90-93] (with some inconsistencies $[71,94,95]$, possibly related to recency of trauma [96]), while a hyperactive HPA axis often accompanies adult depression [71, 97-99], a pattern considered especially characteristic of females [71]. Further findings in schoolage children $[69,81,82,100]$ also suggest that mainly the combination of internalizing symptoms and maltreatment coincides with HPA axis dysregulation (e.g. flatter diurnal decline) while either one of these alone yields cortisol patterns comparable to controls.

As well, most stress response studies focus on glucocorticoids as effector hormones of the HPA axis. However, glucocorticoids are part of a balanced metabolic cascade, and homeostasis of the glucocorticoid metabolism is required for a fully functional stress hormone regulation [101, 102]. This calls for assessments at various tiers of the metabolic cascade to gain a fuller picture of the trauma-related anomalies in neuroendocrine functioning.

Finally, previous research has often set out to examine trait-like long-term patterns in cortisol secretion (i.e., modulation of allostatic set-points; [101]). However, obtaining valid estimates of long-term cortisol levels has been methodologically challenging using assessments in blood, saliva or urine which reflect short-term hormone levels and may suffer from measurement error and situational confounding [103-105].

Meeting the need for a measure of longer-term cortisol secretion, one of our labs has pioneered the measurement of cortisol in hair (see [106]). As cortisol is assumed to be incorporated into the hair shaft during hair growth, the examination of cortisol in a specific hair segment should provide a retrospective index of cumulative cortisol secretion over the time period during which the hair segment has grown [107, 108]. Recently, promising results link hair cortisol levels to differential levels of stress-exposure in adolescents [109] as well as internalizing disorders in adults [77, 93, 99]. However, little or no work to date extends these findings to younger children or wellcharacterized maltreated populations. More generally, work on HPA axis functioning lacks large-scale investigations of developmental samples, integrating neuroendocrine measures with genetic and psychological data. 


\section{Epigenetic programming}

Animal studies and an increasing number of human findings now suggest that epigenetic, experiencedependent modifications of genes related to stress response regulation are involved in long-term imbalance of the HPA axis and may thereby sculpt developmental pathways. In their seminal work, Weaver and colleagues [110] demonstrated that maternal caregiving behavior in rodents (e.g., licking, grooming, arched-back nursing) affected hippocampal glucocorticoid receptor (GR) function via epigenetic programming including DNA methylation and histone modification. Unless treated pharmacologically, these effects persisted into adulthood with long-term impact on stress response and behavior. Likewise, differences in N3RC1 promoter methylation and corresponding changes in glucocorticoid receptor mRNA were found in post-mortem hippocampal sections of suicide victims, which varied as a function of experienced childhood abuse, thus suggesting a parallel effect of early parental care on epigenetic regulation of GR expression in humans [111]. Recent studies point to genotype-specific role of the DNA methylation in the FKBP5 gene with respect to infant neurobehavioral development [112] and risk for adult stress disorders [113]. As NR3C1 and FKBP5 are key modulators of the stress response and HPA axis regulation, epigenetic programming linked to early adversity may be of special importance for development of internalizing disorders, in turn, effecting changes in the HPA axis, among others [114-116]. Yet, little work in humans examines these epigenetic mechanisms as they take shape during ongoing development.

\section{E. Psychological processing of maltreatment and social support} Psychological processing of early adversity and the individual social support available to the child, may also explain unique variance in the diverse pathways of risk [117], including the dysregulation of the HPA axis following deleterious rearing experiences [100]. For example, a study by one of our labs [118], supports the notion that it is the child's representation of caregivers rather than caregiving environment per se that gives rise to elevated risk of behavioral symptoms in preschoolers. Indeed, recent neural data suggest that insecure attachment representations of caregivers also give rise to negative expectations during future interactions with unfamiliar peers, thus providing first empirical support to the neurocognitive mechanism driving the influence of representations across development [119, 120]. Further studies of ours [121-124] and other groups $[125,126]$ suggest that narrative techniques are appropriate from preschool age and aid in the detection and prognosis of gender-specific cognitive emotional styles that act as risk/protective factors for behavioral and internalizing symptoms. A number of groups [127-132] have identified ample cognitive emotional styles in maltreated children (e.g., dissociation, negative caregiver representations). In turn, these factors partly mediate effects of maltreatment on the level of social competence [133] and behavioral symptoms [134], underscoring their influence on developmental pathways.

\section{F. Multiple perspectives on developmental outcome}

Finally, when mapping pathways, it is crucial to assess mental health outcome in children in a highly accurate manner. To date, there has been a strong reliance in the maltreatment literature for young children on brief questionnaires, often completed by single external informants (e.g. parents). Data from one of our labs [135] and others $[136,137]$ demonstrate that is possible to maximize accuracy in outcome assessment by sampling multiple psychological perspectives on mental health problems, including those of children, parents, and teachers.

\section{Study aims}

Owing to the aforementioned gaps in the evidence base we seek to:

1. describe and quantify different patterns/clusters of children with maltreatment experiences and/or psychopathological symptoms (e.g., internalizing, externalizing, healthy), drawing on a multi-method, multi-informant approach [136] to assess maltreatment and psychopathology via age-appropriate, reliable and valid interview, self-, parent- and teacher-reports;

2. identify factors that predict mental health problems, especially internalizing symptoms: duration, severity, quality, and time of maltreatment, family/social support, cognitive emotional styles, and genetic variants, especially in genes previously identified as potential susceptibility factors for internalizing disorders; farther, we aim to evaluate effects of dysregulation of the neurobiological stress system in terms of cortisol secretion;

3. evaluate the interaction of these factors, especially the mediating role of the neurobiological stress system and the roles of gender and genetic variants in stress-response related genes as moderators of associations between maltreatment experiences and internalizing symptoms;

4. explore possible etiopathological mechanisms in a subgroup of children related to altered steroid metabolism or epigenetic modification leading from adverse maltreating environment to emergence of psychopathological (especially internalizing) symptoms and disorders. 


\section{Methods/design \\ Samples}

We will draw on two existing large-scale samples in Leipzig (Samples 1 and 2) and two additional samples (Samples 3 and 4), recruited expressly for AMIS from child protection services (CPS) Leipzig and Munich. Leipzig is a city in eastern Germany, with a population of 500,000, and above-average rates of families living in poverty. Munich is a metropolis (1.35 million inhabitants) in southern Germany with less poverty relative to Leipzig, but a high number of immigrant families.

Sample 1: For the current project, we aimed to remobilize $\sim 90 \%$ of a sample of 251 children originally oversampled for internalizing symptoms at preschool age [138]; first assessment funded by the German Research Foundation, KL 2315/1-1). Also, we sought to recruit an additional 75 children for a second wave of basic datacollection yielding a total subsample of $\mathrm{N}=300$. Children will be aged 4-8 years. Relevant variables/information were collected prior to AMIS (e.g. internalizing symptoms and disorder, saliva cortisol under stress conditions, genotyping).

Sample 2: Within AMIS we also aimed to reactivate roughly $60 \%$ of a sample of 751 children, yielding a total subsample of $\mathrm{N}=\sim 450$ children. This sample was originally comprised of 285 clinically referred children and 466 children from the general population, as part of the "B4a - LIFE Child Depression" cohort of the "Leipzig Research Center for Civilization Diseases, University of Leipzig" (LIFE, funded by the European Union, by the European Regional Development Fund/ERDF and the Free State of Saxony within the framework of the excellence initiative). Various data were collected at a first assessment (e.g., comprehensive diagnostic assessment, genotyping, see Tables 1 and 2) between 2011 and 2014. For AMIS children will be aged 9-16.

Sample 3: We will recruit $\mathrm{N}=150$ maltreated children and their caregivers, receiving interventions from the Leipzig Child Protection Service (CPS) due to maltreatment, including those taken into custody in accordance with the law (\$ 42 SGB VIII; Age range: 4-16 years).

Sample 4: 70 maltreated children, aged 9-14 years with severe maltreatment will be recruited using a comparable protocol as under 3) by the Munich CPS.

Prior research on maltreatment in these age-groups (<16 years) [1-4, 6-8, 22, 139-141] leads us to expect a balanced gender distribution in all samples, but higher incidences of (a.) sexual abuse in girls and (b.) overall maltreatment in our clinically referred sample.

\section{Inclusion criteria for all samples}

Participation is conditional upon the informed consent from legal guardians and assent of the child. To be eligible for the study, caregivers and children must speak
German at a sufficient level and children's cognitive development must be within the normal range (i.e., excluding severe mental impairment) as deficits in these areas may otherwise interfere with the comprehension and completion of measures.

\section{Compensation for participation and sample maintenance}

Caregivers will receive monetary compensation to take part in the study. Compensation will vary with the extent of time required for the investigations. Children will receive a small gift for their participation. Previous research experience shows that compensation is imperative for the establishment and maintenance of developmental samples. In order to maintain contact with families prepared to participate, measures for sample maintenance will be implemented (e.g., Birthday and Christmas greetings to the child, postcards to inform us of changes in address or contact details, etc.).

\section{Recruitment procedure}

Recruitment of most families in Samples 1 and 2 took place as part of previous research. Additional families in Sample 1 will be recruited through two channels: (1.) routine medical check-ups of the Health Department of Leipzig assessing school readiness and (2.) via ads and flyers in kindergartens. Caregivers will be informed about the study and invited to participate. Should families express interest to take part, they will receive written information about the project along with consent forms. An appointment for the investigation will be arranged via phone and confirmed a few days in advance.

Research fellows situated within the CPS will be in charge of recruitment of Samples 3 and 4. These fellows will select and contact participants in accordance with the inclusion criteria via CPS social workers. If necessary, joint home visits of the project associate and the CPS worker will take place in selected families to provide oral and written information concerning the research project. If caregivers and children agree to participate, written consent for participation and access to CPS records will be ascertained. Subsequently, appointments with caregivers and child will be arranged.

\section{Data-collection}

For Samples 1 and 2, comprehensive data from a first wave of data-collection will be available. Additional assessments will take place in these samples. In brief, the following types of data will be collected in the respective samples:

Sample 1: Caregivers and teachers will complete questionnaires while caregivers and children will be interviewed to assess maltreatment experiences, social support, emotion regulation (see Tables 1 and 2). Also, we will collect hair 
Table 1 Assessment of trauma/maltreatment, psychopathology, psychosocial factors, and physical development

\begin{tabular}{|c|c|c|c|c|c|c|}
\hline \multirow{2}{*}{$\frac{\text { Variables }}{\text { Child abuse and neglect }}$} & \multirow[t]{2}{*}{ Measures } & \multirow[t]{2}{*}{ Source } & \multirow[t]{2}{*}{ Informants } & \multicolumn{2}{|c|}{ Age groups } & \multirow[t]{2}{*}{ Samples } \\
\hline & & & & $4-8$ & $9-14$ & \\
\hline \multirow[t]{4}{*}{ Severity, subtypes, timing, frequency, perpetrator } & - MCS & Official documents & CPS file & $x$ & $x$ & 3,4 \\
\hline & - CTS-PC & Interviews & Caregiver & $x$ & $x$ & $1-4$ \\
\hline & - MNBS & Questionnaires & Caregiver, Child & & $x$ & $1-4$ \\
\hline & & Interviews (Picture-based) & Child & $x$ & & $1-4$ \\
\hline \multicolumn{7}{|l|}{ Psychopathology } \\
\hline General Symptoms & - $\mathrm{CBCL}$ & Questionnaire & Caregiver & $x$ & $x$ & $1-4$ \\
\hline \multirow[t]{4}{*}{ (dimensional) } & - SDQ & Questionnaire & Caregiver, Child, & $x$ & $x$ & $1-4$ \\
\hline & & & Teacher & $x$ & $x$ & $1-4$ \\
\hline & - YSR & Questionnaire & Child & & $x$ & $2-4$ \\
\hline & - $\mathrm{BPI}$ & Puppet Interviews & Child & $x$ & & $1,3,4$ \\
\hline Internalizing Symptoms & - CES-DC & Questionnaire & Caregiver, Child & $x$ & $x$ & $1-4$ \\
\hline \multirow[t]{3}{*}{ (dimensional) } & - SCARED & Questionnaire & Caregiver, Child & $x$ & $x$ & $1-4$ \\
\hline & - CHILD-S & Questionnaire & Caregiver & $x$ & $x$ & $2-4$ \\
\hline & - ETI-CA & Questionnaire & Caregiver, Child & $x$ & $x$ & $1-4$ \\
\hline Psychiatric disorders & - K-SADS-PL & Interview & Caregiver & $x$ & $x$ & $2^{a}, 3,4$ \\
\hline (categorical) & - PAPA & Interview & Caregiver & $x$ & $x$ & $1^{\mathrm{a}}, 3$ \\
\hline \multicolumn{7}{|l|}{ Child environment } \\
\hline Social support & - ASSIS & Interview & Child, Parent & $x$ & $x$ & $1-4$ \\
\hline Peer environment & - PVS & Questionnaire & Child, Teacher & $x$ & $x$ & $1-4$ \\
\hline \multirow[t]{4}{*}{ Family environment } & - FES & Questionnaire & Caregiver & $x$ & $x$ & $1-4$ \\
\hline & - $\mathrm{CTQ}$ & Questionnaire & Caregiver & $x$ & $x$ & $1-4$ \\
\hline & - CIPA & Questionnaire & Caregiver & $x$ & $x$ & $1-4$ \\
\hline & - $\mathrm{APQ}$ & Questionnaire & Caregiver & $x$ & $x$ & $1-4$ \\
\hline \multirow[t]{3}{*}{ Caregiver factors } & - $\mathrm{PHQ}$ & Questionnaire & Caregiver & $x$ & $x$ & $1-4$ \\
\hline & • CTQ & Questionnaire & Caregiver & $x$ & $x$ & $1-4$ \\
\hline & - BSSS & Questionnaires & Caregiver & $x$ & $x$ & $1-4$ \\
\hline \multirow[t]{2}{*}{ Overall Adversity } & • ETI, ETI-KJ & Questionnaire, Interview & Child, Caregiver & $x$ & $x$ & $1-4$ \\
\hline & - $\mathrm{FAl}$ & Questionnaire, Interview & Child, Caregiver & $x$ & $x$ & $1-4$ \\
\hline \multicolumn{7}{|l|}{ Psychological factors } \\
\hline Emotion regulation, child representations of caregiver & $\bullet \mathrm{NIT}$ & Child narratives (Video Coding) & Child, parent & $x$ & $x$ & $1-4$ \\
\hline Temperament & - $\mathrm{CBQ}$ & Questionnaire & Caregiver & $x$ & $x$ & $1-4$ \\
\hline Self efficacy & - SPPC-D & Questionnaire & Child & & $x$ & $1-4$ \\
\hline Ego-resiliency & - ERS & Questionnaire & Caregiver, Teacher & $x$ & & $1-4$ \\
\hline Psychological stress-response & $\bullet$ TSST-C & Questionnaire & & & $x$ & 2,3 \\
\hline Social Competences & - SOCOMP & Questionnaire & Teacher & $x$ & $x$ & $1-4$ \\
\hline Callous Unemotional traits & $\bullet$ ICU & Questionnaire & Teacher & $x$ & $x$ & $1-4$ \\
\hline
\end{tabular}


Table 1 Assessment of trauma/maltreatment, psychopathology, psychosocial factors, and physical development (Continued)

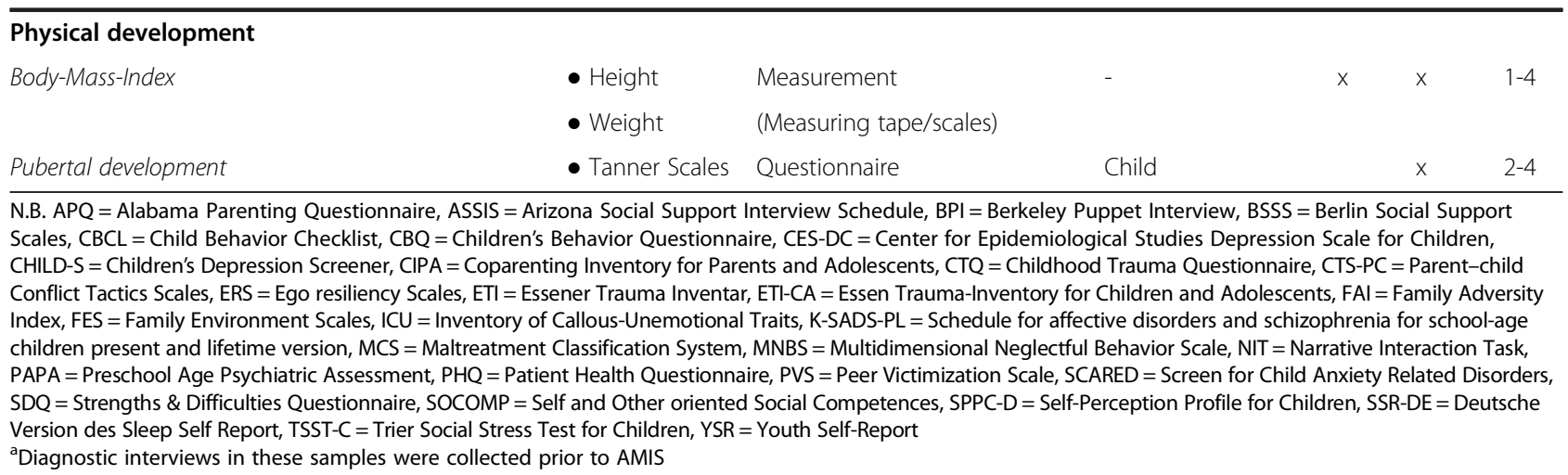

samples from each child (time expenditure: $2 \mathrm{~h}$ individual session with caregiver and child, in parallel).

Sample 2: Children, caregivers, and teachers will complete questionnaires and/or interviews to assess the same constructs as in Sample 1 (see Tables 1 and 2). Hair samples of each child will also be collected (time expenditure: 2 to $3 \mathrm{~h}$ individual session with caregiver and child, in parallel). A subsample of Sample 2 ( $n=25$, plus $n=50$ controls) will take part in an in-depth assessment of stress-regulation (time expenditure: $2.5-3 \mathrm{~h}$ ).

Samples 3 and 4: Data-collection is comprised of two parts for all families. First, assessment of CPS records conducted by CPS research fellows (time expenditure: $3.5 \mathrm{~h}$ per family). Second, two appointments will take place with caregiver and child present. Caregiver and child will be seen in parallel and administered all ageappropriate measures in Samples 1 and 2, as well as clinical interviews. The time expenditure will amount to approximately 2.5-3 h per appointment.

We will videotape all caregiver and child interviews for assessment purposes. Diagnostic interviews will follow a standardized protocol. Hair samples and genetic data of the child will not be collected in Sample 4 in compliance with local legislation in Munich. Caregivers will be asked to complete questionnaires at home between the two appointments and return them to the AMIS team. Teachers of the child will be asked to complete teacherreports which are sent to them by mail. Third, a subsample of sample 3 ( $n=25$; age $9-14$ years) will be invited to take part in an in-depth assessment of stress-regulation (time expenditure: $2.5-3 \mathrm{~h}$ ).

\section{Ethics approval}

The study has been approved by the respective ethics committees of the Universities of Leipzig and Munich, Germany (registration numbers for Leipzig Samples 1 and 2 178-12-21052012, Leipzig Sample 3, 098-12-05032012, and Munich Sample 4 098-12-05032012). Parents are informed orally and in written form about the contents and aims of the study and must give their written consent in order to enroll. All participation is voluntary and may be withdrawn by the family at any time without penalty or consequences of any kind. All procedures are in accordance with the Helsinki declaration. For more intensive neurobiological assessments (e.g., blood draws during stress protocol) numerous safety measures have been put in place (e.g., exclusion of children with acute and severe psychopathology; positive feedback to children at the end of the task; children are accompanied by a caregiver to and from the lab).

Table 2 Assessment of child neurobiological and genetic factors

\begin{tabular}{|c|c|c|c|c|c|c|}
\hline Variables & Source & Measure & Assessment & Age & roups & Samples \\
\hline Neurobiological factors & & & & $4-8$ & $9-14$ & \\
\hline Chronic stress exposure & - Hair & - Cortisol & Normal appointment & $x$ & $x$ & $1-4$ \\
\hline Genomic mechanisms & - Plasma/Saliva & $\begin{array}{l}\text { - Steroid metabolomics } \\
\text { - Methylation }\end{array}$ & Trier Social Stress Test for Children (TSST-C) & & $x$ & $2^{\mathrm{a}}, 3^{\mathrm{a}}$ \\
\hline Stress response regulation & $\begin{array}{l}\text { - Saliva } \\
\text { - Plasma }\end{array}$ & $\begin{array}{l}\text { - Saliva cortisol } \\
\text { - Blood cortisol } \\
\text { - a-Amylase }\end{array}$ & TSST-C & & $x$ & $2^{\mathrm{a}}, 3^{\mathrm{a}}$ \\
\hline
\end{tabular}

Genomic factors

Susceptibility genes

- Saliva/Plasma - Focus on HPA-axis-related genes

Normal appointment

$\times \quad x$

$1-4$

${ }^{\mathrm{a}}$ TSST-Cs will only be conducted in a subsample of $\mathrm{N}=80-100$ children 


\section{Measures}

Detailed descriptions measures will follow below, with an emphasis on key novel instruments (see Table 1). We only give cursory attention to widely used and wellknown measures or assessments secondary to the main hypotheses. In the following sections, we refer to any responsible adult who has had close and regular contact to the child for a significant amount of time as "caregiver". For data-acqusition in AMIS, this person acts as the primary external informant as many children will not be residing with their biological parents.

\section{Patterns of childhood maltreatment and adversity}

It is very challenging to operationalize maltreatment for several reasons: due to social stigma attached to it, because it usually occurs in private (i.e. without external observers), and as disclosure may lead to severe consequences [142]. Bearing these difficulties in mind, we will ascertain characteristics of maltreatment with a comprehensive, multi-source (interviews, self- and caregiverreports), multi-informant (child, parent) strategy in all samples to minimize false-negative cases, in particular. For samples 3 and 4, we will also conduct an intensive standardized evaluation of CPS records, respectively, as is common practice in this field ( $3.5 \mathrm{~h}$ per record). In cases of new disclosures that require immediate action due to ongoing risk to the child, we have put measures in place (e.g., reporting cases to CPS or for cases known to CPS, intensifying interventions, if necessary).

Interviews with the caregiver and analyses of CPS records will be rated using the Maltreatment Classification System (MCS) [143] - a highly accurate, comprehensive, widely used and validated standardized system to evaluate maltreatment events reported in CPS records and caregiver interviews, based on the Maternal Maltreatment Classification Interview (MMCI) [144]. The MCS will serve as the basis for our assessment of case records (CPS) as well as our interviews to optimize comparability between our different samples and to ongoing international research. The MCS distinguishes between all major subtypes, i.e., neglect, including failure to provide and lack of supervision, sexual, physical, and emotional maltreatment (the latter includes witnessing parental violence), describes anchor examples, and formulates inclusion and exclusion criteria for each of these. Also, all relevant dimensions of maltreatment (subtype, severity, frequency/chronicity, developmental period, separations/ placements, perpetrator) are coded for each incident. One of the authors (Jody T. Manly, PhD) provided onsite training and helped to adapt the MCS to a German environment. Interviews with caregivers of affected children last approximately 45-60 min, while interviews with caregivers of unaffected children usually last between 10-30 min.
Children will additionally be requested to self-report on their child abuse and neglect experiences, using an adaptation of the Multidimensional Neglectful Behavior Scale (MNBS) and the Parent-child Conflict Tactics Scale (CTS-PC), with pictorial versions for children $\leq 8$ years (15-20 min. each) $[145,146]$. Further, we will administer the Essen Trauma-Inventory for Children and Adolesents (ETI-CA) $[147,148]$ and the Family and Life Events Sections of the Preschool Age Psychiatric Assessment (PAPA) $[149,150]$ to all caregivers and older children ( $\geq 9$ years) to evaluate presence of critical life events.

\section{Psychiatric symptoms and diagnoses}

Psychiatric symptoms We will quantify psychiatric symptoms using a multi-method, multi-informant approach, drawing on caregiver-, teacher- and child-ratings via reliable and valid questionnaires and interviews as well as age-appropriate puppet interviews [136]. To this end, caregivers and teachers will complete the Strengths and Difficulties Questionnaire [151], a 25-item screening measure, with good rates of compliance from parents and teachers due to its brevity. The 25 questions encompass four symptom scales (behavior problems, emotional problems, hyperactivity, and peer problems) and prosocial behavior. To assess total difficulties the scores of the four symptom scales are summed. Additionally, caregivers will complete the Child Behavior Checklist (CBCL) [152], a robust and broadly validated caregiverreport instrument. The questionnaire encompasses symptom scales which are grouped under internalizing syndrome (Withdrawn, Somatic Complaints, Anxious Depressed) and externalizing syndrome (Rule-breaking Behavior, Aggressive Behavior). By using the existing German norms for these measures e.g., [153, 154], the scores can be categorized into three groups: normal, borderline, or abnormal.

As the focus lies on internalizing symptoms, all caregivers will additionally complete the 20-item Center for Epidemiological Studies Depression Scale for Children (CES-DC) [155] and the 41-item Screen for Child Anxiety Related Emotional Disorders (SCARED) [156]. Further, we will administer the Essen Trauma-Inventory for Children and Adolesents (ETI-CA) $[147,148]$ to all caregivers and older children ( $\geq 9$ years) to gauge PTSD symptomatology.

Children aged nine and above will complete a number of self-reports. First, we will collect the child-adapted version of the SDQ and the Youth Self Report (YSR) which assesses the same dimensions as the CBCL [157, 158]. Second, children in this age band will also complete the child versions of the CES-DC, SCARED and ETI-CA as well as the Children's Depression Screener (ChilD-S) [159]. 
Children aged 8 and younger will be requested to complete the Berkeley Puppet Interview (BPI) $[137,160]$ to assess children's self-perceptions of symptoms. The BPI blends structured and clinical interviewing techniques to elicit the child's own perspective of their strengths and difficulties. Experimenters conduct interviews with the help of two identical hand puppets that make two opposing statements on a topic before asking children to describe themselves. Independent raters will score interviews from videos. The BPI has undergone extensive testing for reliability and validity with preschoolers e.g., [137, 161]. Each interview lasts $30 \mathrm{~min}$. Interviewers and coders receive intensive on-site training.

Psychiatric disorders Internationally well-established structured diagnostic interviews will be employed to derive concurrent categorical diagnostic classifications in Samples 3 and 4. They will parallel those already collected in Samples 1 and 2: the Preschool Age Psychiatric Assessment (PAPA) [149, 150], for younger children in Sample 3 and the Schedule for Affective Disorders and Schizophrenia for school-age children, Kiddie-SADSPresent and Lifetime Version (K-SADS-PL) [162] in Samples 3 and 4 . The PAPA is a comprehensive, structured, glossary-based psychiatric interview for assessing psychiatric symptoms, symptom scale scores, and diagnoses, as well as life events, family structure and functioning, and impairment in children aged 2 to 8 . The PAPA provides a standardized measure of DSM-IV psychiatric symptoms and disorders in preschoolers. An electronic version of the PAPA, the ePAPA, enables administration by touchscreen-based laptops. All relevant data are recorded directly in the ePAPA interface, allowing for fast, automated assessment. Research assistants will conduct interviews with caregivers, lasting approximately $2.5 \mathrm{~h}$, but may take longer in cases with high symptom-load.

The K-SADS-PL is a semi-structured interview based on DSM-IV and assesses current and lifetime history of psychiatric disorders of children. The K-SADS-PL consists of a screening interview and six diagnostic supplements. All participants are initially screened, followed by supplemental questions when screened positive. The interview will be conducted with caregivers, lasting approximately $2 \mathrm{~h}$. Trained members of one of our labs have extensive experience using and coding the PAPA and K-SADS-PL. They will provide training to all AMIS staff using these interviews in Samples 3 and 4.

\section{Psychological measures}

We will assess cognitive-emotional styles of children with self-reports and narrative techniques (often used to study psychological processing of trauma) [30, 117, 127,
130, 131]. Teachers and parents will complete the Ego Resiliency Scales [163]. Also, parents will be enquired about their child's temperament using the Children's Behavior Questionnaire [164], and all children will be asked to complete Harter's Self-Perception Profile for Children (SPPC) [165] to assess their self concept. Teachers will also complete the Inventory of Callous Unemotional Traits [166, 167].

Narrative techniques, in particular, have aided in the identification of gender-specific patterns and risk/protective factors for behavioral symptoms in children [118, 121-123, 125-127, 130, 131] as well as abnormal cognitiveemotional styles in maltreated samples, e.g.[127-133]. We will use a narrative interaction task informed by the MacArthur Story Stem Battery (MSSB) [168] and narrative-co-construction techniques. Children's narrative responses following six story stems will be videotaped and rated with codes based on the MacArthur Narrative Coding Manual (MNCM) [169] and the Process Scales [170]. The narratives will be coded for content (e.g. negative representation of mother) and structure (e.g. coherence, denial, intentionality). The procedure is suitable for children age four and above. The procedure takes about 20 min with an additional 30 min required for coding.

\section{Measures of social relationships}

Social support We will administer the Berlin Social Support Scales (BSSS) [171] to parents as well as Barerra's $[172,173]$ Arizona Social Support Interview Schedule (ASSIS) to parents and children - a relatively brief interview (20-30 min.) previously used in children as young as 5 years $[55,174]$. It operationalizes a child's social network by requesting, for example, whom he/she can confide in when he/she wants to talk about personal issues or count on to purchase needed materials/objects. Next, the child rates the extent of contact he/she has to each social support and how much this person is perceived as caring. The child version of the ASSIS has proven highly successful in identifying the protective effects of social support: (a.) for childhood depression [173], (b.) for the combined negative impact of child depression and maltreatment on HPA axis dysregulation [100] and (c.) for children who carry risk genotypes for child depression following maltreatment $[55,174]$.

Socioeconomic burden Socioeconomic status will be indexed by the Winkler Index [175], which takes into account educational as well as occupational status and income of caregivers. We will also use the Family Adversity Index (FAI) [176], which assesses important risk factors, such as low parental education, overcrowding in the family, persisting parental discord or one-parent family situation, maternal psychopathology, delinquency of the father, institutional care of the child exceeding one 
week in duration. The presence of each item is scored as 1 point and the total number is summed. The FAI has been of considerable importance in showing the link between family stressors and disorder in the child.

Family life The Alabama Parenting Questionnaire (APQ) $[177,178]$ will be adminstered to assess six parenting constructs: (1) Parent Involvement, (2) Positive Parenting, (3) Poor Monitoring/Supervision, (4) Inconsistent Discipline, (5) Corporal Punishment, and (6) Other Discipline Practices. Parents and older children will serve as informants. The quality of family relationships will be assessed via parental ratings using the German version of the Family Environment Scale (FES) [179, 180]. We will use the average score of the subscales cohesion, expressiveness and conflict to establish the quality of family relationships.

\section{Neuroendocrine biomarkers of stress and stress response regulation}

We have chosen two strategies to assess HPA axis functioning. These include (i) the innovative approach of measuring cortisol concentration in hair as a biomarker of chronic stress exposure and (ii) a well- established protocol to assess acute cortisol stress reactivity under standardized conditions (see Table 2).

Hair cortisol concentration (HCC) An important aspect of the current proposal is the assessment of stable changes in cortisol secretion which are influenced by maltreatment in early childhood and persist throughout adolescence and adulthood. The assessment of cortisol in hair constitutes an innovative method which is assumed to provide an index of stable, long-term cortisol secretion. As cortisol is assumed to be incorporated into the hair shaft during hair growth, the concentration of cortisol in a specific hair segment should provide retrospective index of cumulative cortisol secretion over the specific time period of hair growth [107, 108]. Hair strands of a diameter of approximately $3 \mathrm{~mm}$ will be taken scalp-near from a posterior vertex position using fine scissors. Steroid concentrations in the two $3 \mathrm{~cm}$ hair segments most proximal to the scalp will be determined. Based on a hair growth rate of $\sim 1 \mathrm{~cm} /$ month [181], these hair segments are assumed to represent cumulative steroids secreted over the 6-months period prior to hair sampling.

Over the past decade, the use of hair cortisol as an index of long-term cortisol secretion has been supported by considerable evidence, indicating both high test-retest reliability [182] and general validity of the method [183-188]. In addition, evidence has confirmed marker qualities of hair cortisol levels with regard to chronic psychosocial stress [189-192] as well as in the context of stress-related diseases [193-195]. Furthermore, hair cortisol has proven relatively robust to a range of potential hair-related confounding influences including dyeing, bleaching, straightening or permanent waves; [185, 196-198], though hair washing frequency and chemical hair treatments should be assessed and controlled for [199]. Besides hair-related parameters, it has been shown that age [200] and body fat-related measures [106, 201] may be associated with hair cortisol levels and should be considered as potential covariates.

Stress response regulation To assess Salivary and plasma cortisol levels in response to a standardized stressor, we will administer the Trier Social Stress Test (TSST) [202-204] in its child-adapted form for Children (TSST-C) [204] to a subset of Samples 2 and $3(n=80$ 100; $9-14$ years). The sample will comprise children with internalizing symptoms or disorders and a history of maltreatment as well as non-maltreated controls.

The TSST is a standardized protocol that has been found to produce the most significant and reliable HPA axis activation under laboratory conditions in a metaanalysis [205]. It is a resource-intensive procedure with a duration of about three hours, requiring participation of up to four staff members. Besides measures of the HPA axis, we will analyze salivary amylase activity as a proxy of sympathetic activation [206] as well as steroid metabolomic factors and gene methylation (see below).

Steroid metabolomics Change in cortisol levels is the most accessible read-out of the human stress response. However, cortisol is embedded in complex metabolomic processes limiting the information that can be provided by a single element of the steroid pathway [207]. In this study we are planning to measure additional steroids to obtain a complete picture of the corticosteroid pathway. It can be assumed that a disturbed balance of the steroid pathway is a major contributing factor for the medium and long-term effects of stress including the risk of developing stress-related mental disorders. Therefore, we will investigate the effects of a disturbed steroid metabolism on risk of psychopathology by evaluating corticosteroid and neurosteroid metabolites from plasma samples obtained in response to the TSST. These analyses will include the assessment of the precursors and metabolites of cortisol including 11-deoxycortisol and cortisone, the mineralcorticoid aldosterone and its precursor steroids 11-deoxycorticosterone and corticosterone, as well as the neuroactive steroid hormones dehydroepiandrosterone (DHEA) and dehydroepiandrosterone-sulfate (DHEA-S) as well as its metabolite androsterone. In addition, we will evaluate the androgen steroids androstenedione, testosterone and dihydrotestosterone or the progestogens progesterone and 17a-hydroxyprogesterone as well as estradiol to obtain a complete picture of gender- 
dependent stress effects on the steroid metabolism. Steroid metabolomic analyses will be performed using liquid chromatography in combination with mass spectrometry (LC-MS/MS).

\section{Genetic assessments}

Genetic moderators Genetic variations are further potential moderators for stress and disease risk. The analyses focus on HPA axis-related genes and will be conducted using the following procedures:

a) Selection of candidate genes identified from previous genetic case/control studies of internalizing disorders (e.g., SLC6A4, TPH2, GRIK3, P2RX7, BDNF, DISK1, ACE, NR3C1/GR, SLC6A15), from genetic stress response and gene-environment studies (e.g., NR3C1/GR, NR3C2/MR, FKBP5, FKBP4, STAT5B, CRHR1), and from the results of a Gene Ontology analysis focusing on the GO term "regulation of response to stress" (GO 0080134).

b) DNA extraction from salivary (Oragene sampling devices) or blood samples (EDTA whole blood) depending on the sample and age of children; DNA extraction will be performed using respective Puregene extraction kits (Gentra).

c) high-throughput DNA genotyping (all samples, $\mathrm{N}=850$ ) using Illumina HumanOmniExpress BeadChip providing a SNP coverage with an average distance of $2.1 \mathrm{~kb}$ for 200 candidate genes selected from a) SNPs tagging regions with copy number variations $(\mathrm{CNV})$ will also be included. Genotyping will be performed with an Illumina iScan System.

We expect $95 \%$ of participants with central European ethnic background. Nevertheless we will perform analyses with and without ethnic minority populations.

DNA methylation Given the prominent role of NR3C1 (GR) and FKBP5 for the stress response regulation, epigenetic assessment will be specifically focused on these two genes, but genes showing maltreatment interactions with respect to disease risk (Aim 3) will also be included. Epigenetic analyses will be conducted with genomic DNA collected from the participants of the TSST study. DNA will be isolated from salivary samples and from blood cells using Puregene (Gentra) extraction kits. Methylation patterns within the promoter regions of the selected genes will be quantified using bisulfite conversion with a Quiagen DNA methylation kit. Methylationspecific primers will be designed using the Methyl Primer Express Software (Applied Biosystems), and sequencing will be conducted using an ABI Prism 3700 capillary sequencer.

\section{Study eligibility}

To ensure sufficient comprehension of child assessments, a number of validated measures of IQ will be administered to children at their first assessment (i.e., Samples 1 and 2 already received their first assessment prior to AMIS). These include Raven's Coloured or Standard Progressive Matrices (CPM; SPM) [208, 209] for younger ( $<8$ years) and older children ( $\geq 8$ years), respectively, as well as the Culture Fair Test 20-Revised (CFT 20-R) [210]. Likewise, linguistic competence will also be assessed at children's first assessment additionally using either the Marburger Sprachverständnistest für Kinder (MSVK) [211] in Sample 1 or the Peabody Picture Vocabulary Test-Revised (PPVTR) $[212,213]$ in all other samples.

\section{Data-analytic procedures}

Data analyses will be based on models of developmental psychopathology [214-217] outlining direct and indirect effects of risk and protective factors on outcomes and how these factors are inter-related. We will test cumulative, mediating and moderating models.

Cumulative models imply, for example, that maltreatment and HPA axis dysregulation are additive risk factors in their effect on internalizing symptoms. Conversely, mediation implies, that, for instance, one risk factor (e.g., abuse) leads to another (e.g., altered gene expression) which, in turn, precipitates internalizing symptoms. Moderation indicates, for example, that a risk factor (e.g., genotype) exerts a weaker effect in the presence of another factor (e.g., social support) than in its absence.

With regard to the analytical framework for genetic analyses, we will mainly apply methods originating from linear models, (e.g., generalized linear models, generalized linear mixed models) where appropriate. Analyses will take a bi- and multivariate form, with testing based on likelihood-ratio and quasi-likelihood methods, depending on the specific structure of the data and verified by permutation and other resampling methods. These methods will allow appropriate control of type I error, also in the context of correlated outcomes and predictors. We will also correct for multiple testing via resampling. To this end, we aim to control for the family-wise type I error rate. The expected number $\mathrm{N}$ of permutations is a function of the asymptotic type I error $\alpha$, for a given value of $\alpha, N$ is set to $100 / \alpha$, i.e. for an $\alpha$-value of $\alpha=0.001$ we will expectedly perform $100 /[0.001]=$ 100,000 permutations. All these analyses will be conducted using $\mathrm{R}$.

Beyond this, and in a more exploratory fashion, we will also perform mediation analyses, structural equation models (using Mplus and R), path analyses and methods from machine learning (e.g., support vector machines, again using implementations in R and MATLAB). The latter methods offer the most efficient solution for 
complex analyses, especially if types of data samples vary as is the case in AMIS.

In a third analytic step, we also plan to use methods to delineate pathways leading from genome and trauma to emergence of psychopathology. Here, we will use both aforementioned approaches and methods aiming to infer causality from observational data, preferentially building on Janzing and Schölkopf's [218] framework. In addition, we will search for gender differences in all our analyses as a possible moderator. Due to the partial heterogeneity in our samples, we will insert sample membership in all analyses as a control variable, to assess whether results are homogenous in all four samples.

\section{Power calculation}

To determine the required total sample size, we focused on Aim 3 addressing the moderating effects of genotype and gender on the association between maltreatment and disease risk. The core analysis for this aim is a geneenvironment interaction analysis between the genetic variants and maltreatment with respect to the development of internalizing symptoms and disorders. We are intending to select 200 candidate genes, for which we assume an average number of five independent LD blocks within the genes, resulting in 1,000 independent tests. Further, we will perform separate analyses for those interactions with a significant gender effect. We assume that this will increase the number of independent analyses to 1.200. From this number we calculate a Bonferroni-corrected alpha error of $.05 / 1.200=4.17 \mathrm{e}-5$. Based on a total sample size of 850 individuals, we achieve a power estimate of larger than 0.90 for the gene-environment interaction term in case of an effect size of at least $3 \%$ explained variance, even for genotypes with a minor allele frequency of $1 \%$, suggesting sufficient power to detect also small gene-environment interaction effects. Power calculation was conducted with Quanto Version 1.2.3. An additive mode of inheritance was applied, and quantitative variables were assumed for the environmental factor (maltreatment score) and the disease trait (internalizing symptoms).

\section{Discussion}

Our protocol addresses several important areas pertinent to broadening our grasp of different pathways of mental development in the aftermath of maltreatment, including neurobiological, psychological, social, and genomic processes. Though some of these areas have already been studied individually in some detail, in most cases work is currently limited to adults (e.g., hair cortisol) or certain subsets of maltreated populations (e.g., few studies comparing HPA axis functioning in children with emotional abuse or neglect to controls), and small samples of maltreated children (e.g., cognitive-emotional styles). Most importantly, the current collaboration of experts within each of these fields offers the opportunity to move beyond studying these processes in isolation by evaluating how these processes interact with one another to potentiate or reduce risk of internalizing symptoms and disorders following childhood maltreatment.

The greatest challenge for longitudinal studies on consequences of maltreatment lies in the difficulty of recruiting a sufficiently large sample of affected children and families. The majority of affected families suffers poverty and is non-compliant and/or lacks motivation to participate in research. Notwithstanding, we intend to undertake a concerted effort to implement our research strategies by joining forces with the local youth welfare offices/governmental child protection services at the forefront of working with such families. It is therefore of vast strategic importance that we have enlisted the heads of CPS Leipzig and Munich with their practical and research background as members of our research group. This alliance will enable us to carry out our scientific evaluations in samples with a large variance of maltreatment experiences, ranging from relatively transient and mild to chronic and severe.

Although the collaboration with the directors and the staffs of the CPS ensures the feasibility of the study in these populations, we also clearly acknowledge that these assessments will require great efforts: motivating the participating families, many short-notice cancellations of appointments, re-invitations, sometimes extended or repeated visits.

\section{Limitations}

First, in Samples 1 and 2, we will run a second wave of data collection. However, in Samples 3 and 4 only one cross sectional assessment will be possible during the three year funding period. Therefore we will mainly be able to identify risk patterns rather than longitudinal causal chains. For example, data-analysis will not enable us to differentiate whether certain forms of HPA axis dysregulation are caused by maltreatment experiences or by psychopathology or whether they are consequences of reciprocal transactional processes influenced by both environmental and individual aspects of development. In the same vein, our study will mainly inform us about the risk/protective effects of these factors on concurrent mental health, but these may differ in important ways from long-term risk/protective effects [219]. Nevertheless, our careful cross-sectional assessments will serve as a starting point for designing long-term research strategies within a prospective design. Second, samples will be heterogeneous with respect to age and problem levels, which may limit comparability, but will improve generalizability and sensitivity to detect differences and associations. Finally, as is common practice in the field, 
we focus on post-hoc assessments of maltreatment, i.e. after it has taken place. Hence, we will not be in an optimal position to analyze causes for maltreating behavior. Yet, our design takes us much closer in time to the phenomena in question vis-à-vis adult studies that usually rely on distal retrospective reports.

\section{Implications}

Many local and national projects strive to prevent and treat individual and social problems engendered by childhood maltreatment. A common limiting factor is that these efforts suffer from a lack of empirical support and coordination. The proposed project will lead to direct benefits in the field of personalized prevention. The results will extend the evidence base for practice guidelines applicable to all fields of child protection. They will help consolidate a catalogue of risk indicators (biological and psychosocial) that may be ascertained in standardized ways in cases of child maltreatment.

Moreover, there are great efforts to improve interdisciplinary collaboration between the CPS and medical institutions (e.g., paediatric hospitals, child psychiatric departments) to establish common standards in dealing with maltreated children and their families. By means of direct cooperation with the CPS, this protocol extends this collaboration to the field of scientific research in this country, raising the collaborative standards to new and higher levels.

Indeed, many countries have seen various attempts to establish standard procedures in the face of child maltreatment, but these efforts were often not optimally coordinated across different disciplines and often lack empirical basis. Improved knowledge on patterns of psychopathology in the aftermath of maltreatment, risk factors as well as protective factors, and how these factors interact will lay the basis for improved diagnostic standards which are applicable to the fields of social work/ child protection as well as clinical medicine.

In sum, AMIS will contribute substantially to a growing cross-national research effort towards broadening our grasp of differential response profiles of children with a history of maltreatment. In turn, these data will eventually pave the way for more judicious clinical decision-making and elaborating interventions in the wake of maltreatment tailored to the specific needs of the individual child.

\section{Competing interests}

The authors declare no competing interests.

\section{Authors' contributions}

All authors have made substantive intellectual contributions to this project. KvK is the project leader. KvK, MI, CK, MKA are principal investigators of their subprojects and carry overall responsibility for their subprojects. KvK, MI, CK, MKA designed and conceived of the study together with the collaborating investigators LOW, AMK, MU, BMM, and KH. They guided the development of the study protocol until submission of the grant to the German Federal Ministry of Education and Research, and worked out the successful ethics proposal with SSi and TS. AM, AA, JH, MB, AC, SSi and LOW are actively involved in coordination, recruitment and establishment of cohorts. BMM, CW and $\mathrm{Ml}$ offer guidance regarding data-analysis and construction of data-bases. $J K, L R, E G, E N, S S C, M B, A C, A M, A A, S S, A M K$ and LOW have been involved in the execution of the study and data-acquisition. All authors contributed to the manuscript of the study protocol and approved the final manuscript.

\section{Authors' information}

M.I. and K.V.K. share joint senior authorship.

\section{Acknowledgments}

The authors would like to thank Eva-Maria Götz, Stefanie Dehmel, and Julia Kaya for their support in initiating and executing the study in Leipzig and Munich. The authors would also like to thank Prof. Dr. Christoph RehmannSutter for advice on ethical matters, and Christine Telle and Dr. Angela Gierlich for their input in preparing the manuscript and translating ethical approvals. The research presented herein is supported by a grant from the German Federal Ministry of Education and Research (Grant No. 01KR1201A to E) as well as by LIFE - Leipzig Research Center for Civilization Diseases, Universität Leipzig. LIFE is funded by means of the European Union, by the European Regional Development Fund (ERDF) and by means of the Free State of Saxony within the framework of the excellence initiative. The responsibility for the contents of this publication lies with the authors.

\section{Author details}

${ }^{1}$ Department of Child and Adolescent Psychiatry, Psychotherapy and Psychosomatics, University of Leipzig, Leipzig, Germany. ${ }^{2}$ Department of Psychology, Technical University of Dresden, Dresden, Germany. ${ }^{3}$ Stadtjugendamt München (Child Protection Services Munich), Munich, Germany. ${ }^{4}$ Amt für Jugend, Familie und Bildung Leipzig (Child Protection Services Leipzig), Leipzig, Germany. ${ }^{5}$ Max Planck Institute of Psychiatry, 80804 Munich, Germany. ${ }^{6}$ Munich Cluster for Systems Neurology (SyNergy), Munich 81377, Germany. ${ }^{7}$ University of Liverpool, Institute of Translational Medicine, Liverpool L69 3BX, UK.

Received: 2 December 2014 Accepted: 29 May 2015

Published online: 10 June 2015

\section{References}

1. Gilbert R, Widom CS, Browne K, Fergusson D, Webb E, Janson S. Burden and consequences of child maltreatment in high-income countries. Lancet. 2009;373(9657):68-81.

2. Finkelhor D. Childhood victimization: Violence, crime, and abuse in the lives of young people. USA: Oxford University Press; 2008.

3. MacMillan HL, Fleming JE, Trocme N, Boyle MH, Wong M, Racine YA, et al. Prevalence of child physical and sexual abuse in the community. JAMA. 1997;278(2):131-5

4. Edwards VJ, Holden GW, Felitti VJ, Anda RF. Relationship between multiple forms of childhood maltreatment and adult mental health in community respondents: Results from the adverse childhood experiences study. Am J Psychiatry. 2003;160:1453-60.

5. Finkelhor D, Ormrod R, Turner H. Poly-victimization: A neglected component in child victimization. Child Abuse Neglect. 2007:31(1):7-26.

6. Engfer A. Forms of maltreatment of children - definitions, frequencies, attempts at explanatory approaches [Formen der Misshandlung von Kindern Definitionen, Häufigkeiten, Erklärungsansätze]. In: Egle UT, Hoffmann SO, Joraschky P, editors. Sexual Abuse, Maltreatment, Neglect [Sexueller Missbrauch, Misshandlung, Vernachlässigung]. 3rd ed. Stuttgart: Schattauer; 2005. p. 3-19.

7. Häuser W, Schmutzer G, Brähler E, Glaesmer H. Maltreatment in childhood and adolescence - results from a survey of a representative sample of the German population. Deutsches Ärzteblatt. 2011;108(17):287-94.

8. Pillhofer M, Ziegenhain U, Nandi C, Fegert JM, Goldbeck L. Prävalenz von Kindesmisshandlung und-vernachlässigung in Deutschland. Kindheit und Entwicklung. 2011;20(2):64-71.

9. Luntz B, Widom C. Antisocial personality disorder in abused and neglected children grown up. Am J Psychiatry. 1994;151(5):670-4. 
10. Smith CA, Ireland TO, Thornberry TP, Elwyn L. Interaction between the serotonin transporter gene (5-HTTLPR), stressful life events, and risk of depression. Am J Orthopsychiatry. 2008;78(2):173-86.

11. Springer KW, Sheridan J, Kuo D, Carnes M. Long-term physical and mental health consequences of childhood physical abuse: Results from a large population-based sample of men and women. Child Abuse Neglect. 2007;31(5):517-30.

12. Widom CS. The cycle of violence. Science. 1989;244(4901):160-6.

13. MacMillan HL. Commentary: Child maltreatment and physical health: A call to action. J Pediatr Psychol. 2010;35(5):533-5.

14. Widom CS. Posttraumatic stress disorder in abused and neglected children grown up. Am J Psychiatry. 1999;156(8):1223-9.

15. Widom CS, DuMont K, Czaja SJ. A prospective investigation of major depressive disorder and comorbidity in abused and neglected children grown up. Arch Gen Psychiatry. 2007;64(1):49-56.

16. Manly J, Kim J, Rogosch F, Cicchetti D. Dimensions of child maltreatment and children's adjustment: Contributions of developmental timing and subtype. Dev Psychopath. 2001;13(04):759-82.

17. Scott KM, Smith DR, Ellis PM. Prospectively ascertained child maltreatment and its association with dsm-iv mental disorders in young adults. Arch Gen Psychiatry. 2010;67(7):712-9.

18. Hildyard KL, Wolfe DA. Child neglect: Developmental issues and outcomes. Child Abuse Neglect. 2002;26(6-7):679-95.

19. Fergusson DM, Boden JM, Horwood LJ. Exposure to childhood sexual and physical abuse and adjustment in early adulthood. Child Abuse Neglect. 2008;32(6):607-19.

20. van der Vegt E, van der Ende J, Ferdinand R, Verhulst F, Tiemeier H. Early childhood adversities and trajectories of psychiatric problems in adoptees: Evidence for long lasting effects. J Abnorm Child Psychol. 2009;37(2):239-49.

21. Cicchetti D. Resilience under conditions of extreme stress: A multilevel perspective. World Psychiatry. 2010;9(3):145-54.

22. Kazdin AE, Moser J, Colbus D, Bell R. Depressive symptoms among physically abused and psychiatrically disturbed children. J Abnormal Psychol. 1985;94(3):298-307.

23. Ellis BJ, Boyce WT. Differential susceptibility to the environment: Toward an understanding of sensitivity to developmental experiences and context. Dev Psychopath. 2011;23(01):1-5.

24. Bronfenbrenner U. Contexts of child rearing: Problems and prospects. Am Psychologist. 1979;34(10):844-50.

25. Ellis BJ, Boyce WT, Belsky J, Bakermans-Kranenburg MJ, van ljzendoorn $\mathrm{MH}$. Differential susceptibility to the environment: An evolutionaryneurodevelopmental theory. Dev Psychopath. 2011;23(1):7-28.

26. Del Giudice M, Ellis BJ, Shirtcliff EA. The adaptive calibration model of stress responsivity. Neurosci Biobehav Rev. 2011;35(7):1562-92.

27. Bolger KE, Patterson CJ. Pathways from child maltreatment to internalizing problems: Perceptions of control as mediators and moderators. Dev Psychopath. 2001;13(04):913-40.

28. Keiley M, Howe T, Dodge K, Bates J, Pettit G. Timing of abuse: Group differences and developmental trajectories. Dev Psychopath. 2001;13:891-912.

29. Toth SL, Manly JT, Cicchetti D. Child maltreatment and vulnerability to depression. Dev Psychopath. 1992;4(01):97-112.

30. Kim J, Cicchetti D. Longitudinal trajectories of self-system processes and depressive symptoms among maltreated and nonmaltreated children. Child Dev. 2006;77(3):624-39.

31. Kaplow JB, Dodge KA, Amaya-Jackson L, Saxe GN. Pathways to PTSD, Part II: Sexually abused children. Am J Psychiatry. 2005;162(7):1305-10.

32. Kaplow JB, Widom CS. Age of onset of child maltreatment predicts long-term mental health outcomes. J Abnormal Psychol. 2007;116(1):176-87.

33. Burmeister M, McInnis MG, Zöllner S. Psychiatric genetics: Progress amid controversy. Nature Reviews Genetics. 2008;9(7):527-40.

34. Eley TC, Bolton D, O'Connor TG, Perrin S, Smith P, Plomin R. A twin study of anxiety related behaviours in pre school children. J Child Psychol Psychiatry. 2003;44(7):945-60

35. Glowinski AL, Madden PAF, Bucholz KK, Lynskey MT, Heath AC. Genetic epidemiology of self reported lifetime DSM IV major depressive disorder in a population based twin sample of female adolescents. J Child Psychol Psychiatry. 2003:44(7):988-96.

36. Boomsma D, Van Beijsterveldt C, Hudziak J. Genetic and environmental influences on Anxious/Depression during childhood: A study from the Netherlands Twin Register. Gene Brain Behav. 2005;4(8):466-81.
37. Hoekstra RA, Bartels M, Hudziak JJ, Van Beijsterveldt TCEM, Boomsma DI. Genetic and Environmental influences on the stability of withdrawn behavior in children: A longitudinal, multi-informant twin study. Behavior Genetics. 2008;38(5):447-61.

38. Rice F, Harold GT, Thapar A. Assessing the effects of age, sex and shared environment on the genetic aetiology of depression in childhood and adolescence. J Child Psychol Psychiatry. 2002;43(8):1039-51.

39. Rutter M. Commentary: nature-nurture interplay in emotional disorders. J Child Psychol Psychiatry. 2003;44(7):934-44

40. Scourfield J, Rice F, Thapar A, Harold GT, Martin N, McGuffin P. Depressive symptoms in children and adolescents: changing aetiological influences with development. J Child Psychol Psychiatry. 2003;44(7):968-76.

41. Hoefgen B, Schulze TG, Ohlraun S, von Widdern O, Höfels S, Gross M, et al. The power of sample size and homogenous sampling: Association between the $5-H T T L P R$ serotonin transporter polymorphism and major depressive disorder. Biological Psychiatry. 2005;57(3):247-51.

42. Lucae S, Salyakina D, Barden N, Harvey M, Gagné B, Labbé M, et al. P2RX7, a gene coding for a purinergic ligand-gated ion channel, is associated with major depressive disorder. Human Mol Genet. 2006;15(16):2438-45.

43. McQuillin A, Bass N, Choudhury K, Puri V, Kosmin M, Lawrence J, et al. Casecontrol studies show that a non-conservative amino-acid change from a glutamine to arginine in the P2RX7 purinergic receptor protein is associated with both bipolar-and unipolar-affective disorders. Molecular Psychiatry. 2008;14(6):614-20

44. Schiffer $\mathrm{H}$, Heinemann S. Association of the human kainate receptor GluR7 gene (GRIK3) with recurrent major depressive disorder. Am J Med Genet B Neuropsychiatr Genet. 2007;144(1):20-6.

45. Zill P, Baghai TC, Zwanzger P, Schule C, Eser D, Rupprecht R, et al. SNP and haplotype analysis of a novel tryptophan hydroxylase isoform (TPH2) gene provide evidence for association with major depression. Molecular Psychiatry. 2004;9(11):1030-6.

46. Hashimoto R, Numakawa T, Ohnishi T, Kumamaru E, Yagasaki Y, Ishimoto T, et al. Impact of the DISC1 Ser704Cys polymorphism on risk for major depression, brain morphology and ERK signaling. Human Mol Genet. 2006;15(20):3024-33

47. Schumacher J, Jamra RA, Becker T, Ohlraun S, Klopp N, Binder EB, et al. Evidence for a relationship between genetic variants at the brain-derived neurotrophic factor (BDNF) locus and major depression. Biological Psychiatry. 2005;58(4):307-14.

48. Baghai TC, Binder EB, Schule C, Salyakina D, Eser D, Lucae S, et al. Polymorphisms in the angiotensin-converting enzyme gene are associated with unipolar depression, ACE activity and hypercortisolism. Molecular Psychiatry. 2006;11(11):1003-15.

49. van Rossum EFC, Binder EB, Majer M, Koper JW, Ising M, Modell S, et al. Polymorphisms of the glucocorticoid receptor gene and major depression. Biological Psychiatry. 2006;59(8):681-8

50. van West D, Van Den Eede F, Del-Favero J, Souery D, Norrback K-F, Van Duijn C, et al. Glucocorticoid receptor gene-based SNP analysis in patients with recurrent major depression. Neuropsychopharmacology. 2005;31(3):620-7

51. Erhardt A, Czibere L, Roeske D, Lucae S, Unschuld PG, Ripke S, et al. TMEM132D, a new candidate for anxiety phenotypes: evidence from human and mouse studies. Molecular Psychiatry. 2010;647-663.

52. Major Depressive Disorder Working Group of the Psychiatric GC. A mega-analysis of genome-wide association studies for major depressive disorder. Molecular Psychiatry. 2013;18(4):497-511.

53. Franic S, Middeldorp CM, Dolan CV, Ligthart L, Boomsma DI. Childhood and adolescent anxiety and depression: Beyond heritability. J Am Acad Child Adol Psychiatry. 2010;49(8):820-9

54. Caspi A, Sugden K, Moffitt TE, Taylor A, Craig IW, Harrington HL, et al. Influence of life stress on depression: moderation by a polymorphism in the 5-HTT gene. Science. 2003;301(5631):386-9.

55. Kaufman J, Yang B, Douglas-Palumberi H, Houshyar S, Lipschitz D, Krystal J et al. Social supports and serotonin transporter gene moderate depression in maltreated children. Proc Natl Acad Sci USA. 2004;101(49):17316-21.

56. Caspi A, McClay J, Moffitt TE, Mill J, Martin J, Craig IW, et al. Role of genotype in the cycle of violence in maltreated children. Science. 2002;297(5582):851-4.

57. Kaufman J, Yang B-Z, Douglas-Palumberi H, Grasso D, Lipschitz D, Houshyar $S$, et al. Brain-Derived Neurotrophic Factor-5-HTTLPR gene interactions and environmental modifiers of depression in children. Biological Psychiatry. 2006;59(8):673-80. 
58. Cicchetti D, Rogosch FA, Oshri A. Interactive effects of corticotropin releasing hormone receptor 1 , serotonin transporter linked polymorphic region, and child maltreatment on diurnal cortisol regulation and internalizing symptomatology. Dev Psychopath. 2011;23(4):1125-38.

59. Munafo MR, Durrant C, Lewis G, Flint J. Gene environment interactions at the serotonin transporter locus. Biological Psychiatry. 2009;65(3):211-9.

60. Risch N, Herrell R, Lehner T, Liang K-Y, Eaves L, Hoh J, et al. Interaction between the serotonin transporter gene (5-HTTLPR), stressful life events, and risk of depression. JAMA. 2009;301(23):2462-71.

61. Grabe HJ, Schwahn C, Appel K, Mahler J, Schulz A, Spitzer C, et al. Childhood maltreatment, the corticotropin releasing hormone receptor gene and adult depression in the general population. Am J Med Genet B Neuropsychiatr Genet. 2010;153(8):1483-93.

62. Heim C, Bradley B, Mletzko T, Deveau T, Musselman D, Nemeroff C, et al. Effect of childhood trauma on adult depression and neuroendocrine function: sex-specific moderation by $\mathrm{CRH}$ receptor 1 gene. Front Behav Neurosci. 2009;3.

63. Polanczyk G, Caspi A, Williams B, Price TS, Danese A, Sugden K, et al. Protective effect of CRHR1 gene variants on the development of adult depression following childhood maltreatment: replication and extension. Arch Gen Psychiatry. 2009;66(9):978.

64. Ressler K, Bradley B, Mercer KB, Deveau TC, Smith AK, Gillespie CF, et al. Polymorphisms in CRHR1 and the serotonin transporter loci: gene $\times$ gene $\times$ environment interactions on depressive symptoms. Am J Med Genet B Neuropsychiatr Genet. 2010;153(3):812-24.

65. Ising M, Depping A, Siebertz A, Lucae S, Unschuld P, Kloiber S, et al. Polymorphisms in the FKBP5 gene region modulate recovery from psychosocial stress in healthy controls. Eur J Neurosci. 2008;28(2):389-98.

66. Binder EB, Bradley RG, Liu W, Epstein MP, Deveau TC, Mercer KB, et al. Association of FKBP5 polymorphisms and childhood abuse with risk of posttraumatic stress disorder symptoms in adults. JAMA. 2008;299(11):1291-305.

67. Binder EB, Salyakina D, Lichtner P, Wochnik G, Ising M, Pütz B, et al. Polymorphisms in FKBP5 are associated with increased recurrence of depressive episodes and rapid response to antidepressant treatment. Nature Genetics. 2004;36(12):1319-25.

68. Zimmermann $\mathrm{P}$, Brückl T, Nocon A, Binder EB, Uhr M, Lieb R, et al. Interaction of variants in the FKBP5 Gene and adverse life events in predicting the first depression onset: results from a ten year prospective community study. Am J Psychiatry. 2011;168(10):1107-16.

69. Cicchetti D, Rogosch FA. The impact of child maltreatment and psychopathology on neuroendocrine functioning. Dev Psychopath. 2001;13(04):783-804

70. Doom JR, Gunnar MR. Stress physiology and developmental psychopathology: Past, present, and future. Dev Psychopath. 2013;25(4 Pt. 2):1359-73.

71. Heim C, Newport D, Mletzko T, Miller A, Nemeroff C. The link between childhood trauma and depression: Insights from HPA axis studies in humans. Psychoneuroendocrinol. 2008;33:693-710.

72. McCrory EJ, De Brito SA, Viding E. Research Review: The neurobiology and genetics of maltreatment and adversity. J Child Psychol Psychiatry. 2010;51(10):1079-95.

73. Heim C, Nemeroff CB. The role of childhood trauma in the neurobiology of mood and anxiety disorders: Preclinical and clinical studies. Biological Psychiatry. 2001;49(12):1023-39.

74. Hatzinger M, Brand S, Perren S, Stadelmann S, von Wyl A, von Klitzing K, et al. Sleep actigraphy pattern and behavioral/emotional difficulties in kindergarten children: Association with hypothalamic-pituitaryadrenocortical (HPA) activity. J Psychiatr Res. 2010;44(4):253-61.

75. Hatzinger M, Brand S, Perren S, von Wyl A, von Klitzing K, Holsboer-Trachsler E. Hypothalamic-pituitary-adrenocortical (HPA) activity in kindergarten children: importance of gender and associations with behavioral/emotional difficulties. J Psychiatr Res. 2007:41(10):861-70.

76. Rohleder N, Joksimovic L, Wolf J, Kirschbaum C. Hypocortisolism and increased glucocorticoid sensitivity of pro-Inflammatory cytokine production in Bosnian war refugees with Posttraumatic Stress Disorder. Biological Psychiatry. 2004;55(7):745-51.

77. Steudte S, Stalder T, Dettenborn L, Klumbies E, Foley P, Beesdo-Baum K, et al. Decreased hair cortisol concentrations in generalised anxiety disorder. Psychiatry Res. 2011;186(2):310-4.

78. Voderholzer U, Hohagen F, Klein T, Jungnickel J, Kirschbaum C, Berger M, et al. Impact of sleep deprivation and subsequent recovery sleep on cortisol in unmedicated depressed patients. Am J Psychiatry. 2004;161(8):1404.
79. von Klitzing K, Perren S, Klein AM, Stadelmann S, White LO, Groeben M, et al. The interaction of social risk factors and HPA axis dysregulation in predicting emotional symptoms of five- and six-year-old children. J Psychiatr Res. 2012;46(3):290-7.

80. Saridjan N, Huizink A, Koetsier J, Jaddoe V, Mackenbach J, Hofman A, et al. Do social disadvantage and early family adversity affect the diurnal cortisol rhythm in infants? The Generation R Study. Hormones Behav. 2010;57(2):247-54

81. Cicchetti D, Rogosch FA, Gunnar MR, Toth SL. The differential impacts of early physical and sexual abuse and internalizing problems on daytime cortisol rhythm in school-aged children. Child Dev. 2010;81(1):252-69.

82. Hart J, Gunnar M, Cicchetti D. Altered neuroendocrine activity in maltreated children related to symptoms of depression. Dev Psychopath. 1996:8(01):201-14.

83. King JA, Mandansky D, King S, Fletcher KE, Brewer J. Early sexual abuse and low cortisol. Psychiatry Clin Neurosci. 2001;55(1):71-4.

84. De Bellis MD, Baum AS, Birmaher B, Keshavan MS, Eccard CH, Boring AM, et al. Developmental traumatology part I: Biological stress systems. Biological Psychiatry. 1999;45(10):1259-70.

85. Elzinga BM, Roelofs K, Tollenaar MS, Bakvis P, Van Pelt J, Spinhoven P. Diminished cortisol responses to psychosocial stress associated with lifetime adverse events: a study among healthy young subjects. Psychoneuroendocrinol. 2008;33(2):227-37.

86. Nicolson NA, Davis MC, Kruszewski D, Zautra AJ. Childhood maltreatment and diurnal cortisol patterns in women with chronic pain. Psychosomatic Med. 2010;72(5):471-80.

87. Engert V, Efanov SI, Dedovic K, Dagher A, Pruessner JC. Increased cortisol awakening response and afternoon/evening cortisol output in healthy young adults with low early life parental care. Psychopharmacology. 2011;214(1):261-8.

88. van der Vegt E, van der Ende J, Kirschbaum C, Verhulst F, Tiemeier H. Early neglect and abuse predict diurnal cortisol patterns in adults: A study of international adoptees. Psychoneuroendocrinol. 2009;34(5):660-9.

89. Carpenter LL, Carvalho JP, Tyrka AR, Wier LM, Mello AF, Mello MF, et al. Decreased adrenocorticotropic hormone and cortisol responses to stress in healthy adults reporting significant childhood maltreatment. Biological Psychiatry. 2007;62(10):1080-7.

90. Delahanty DL, Raimonde AJ, Spoonster E. Initial posttraumatic urinary cortisol levels predict subsequent PTSD symptoms in motor vehicle accident victims. Biological Psychiatry. 2000;48(9):940-7.

91. Yehuda R, Boisoneau D, Lowy MT, Giller EL. Dose-response changes in plasma cortisol and lymphocyte glucocorticoid receptors following dexamethasone administration in combat veterans with and without posttraumatic stress disorder. Arch Gen Psychiatry. 1995;52(7):583-93.

92. Olff M, Güzelcan Y, de Vries G-J, Assies J, Gersons BP. HPA-and HPT-axis alterations in chronic posttraumatic stress disorder. Psychoneuroendocrinol. 2006;31(10):1220-30.

93. Steudte S, Kirschbaum C, Gao W, Alexander N, Schönfeld S, Hoyer J, et al. Hair cortisol as a biomarker of traumatization in healthy individuals and posttraumatic stress disorder patients. Biological Psychiatry. 2013;74(9):639-46.

94. Inslicht SS, Marmar CR, Neylan TC, Metzler TJ, Hart SL, Otte C, et al. Increased cortisol in women with intimate partner violence-related posttraumatic stress disorder. Psychoneuroendocrinol. 2006;31(7):825-38.

95. Resnick HS, Yehuda R, Pitman RK, Foy DW. Effect of previous trauma on acute plasma cortisol level following rape. Am J Psychiatry. 1995:152(11):1675-7.

96. Steudte S, Kolassa I-T, Stalder T, Pfeiffer A, Kirschbaum C, Elbert T. Increased cortisol concentrations in hair of severely traumatized Ugandan individuals with PTSD. Psychoneuroendocrinol. 2011;36(8):1193-200.

97. Heim C, Mletzko T, Purselle D, Musselman DL, Nemeroff CB. The dexamethasone/corticotropin-releasing factor test in men with major depression: role of childhood trauma. Biological Psychiatry. 2008;63(4):398-405.

98. Heim C, Newport DJ, Heit S, Graham YP, Wilcox M, Bonsall R, et al. Pituitaryadrenal and autonomic responses to stress in women after sexual and physical abuse in childhood. Jama. 2000;284(5):592-7.

99. Dettenborn L, Muhtz C, Skoluda N, Stalder T, Steudte S, Hinkelmann K, et al. Introducing a novel method to assess cumulative steroid concentrations: Increased hair cortisol concentrations over 6 months in medicated patients with depression. Stress. 2012;15(3):348-53. 
100. Kaufman J, Birmaher B, Perel J, Dahl RE, Moreci P, Nelson B, et al. The corticotropin-releasing hormone challenge in depressed abused, depressed nonabused, and normal control children. Biological Psychiatry. 1997:42(8):669-79.

101. McEwen BS. Physiology and neurobiology of stress and adaptation: Central role of the brain. Physiological reviews. 2007;87(3):873-904

102. Krishnan V, Nestler EJ. Linking molecules to mood: New insight into the biology of depression. Am J Psychiatry. 2010;167(11):1305-20.

103. Hellhammer J, Fries E, Schweisthal OW, Schlotz W, Stone AA, Hagemann D. Several daily measurements are necessary to reliably assess the cortisol rise after awakening: State- and trait components. Psychoneuroendocrinol. 2007;32(1):80-6.

104. Lightman SL, Wiles CC, Atkinson HC, Henley DE, Russell GM, Leendertz JA, et al. The significance of glucocorticoid pulsatility. Eur J Pharmacol. 2008;583(2-3):255-62.

105. Stalder T, Evans P, Hucklebridge F, Clow A. State associations with the cortisol awakening response in healthy females. Psychoneuroendocrinol. 2010;35(8):1245-52.

106. Stalder T, Steudte S, Alexander N, Miller R, Gao W, Dettenborn L, et al. Cortisol in hair, body mass index and stress-related measures. Biological Psychology. 2012;90(3):218-23.

107. Gow R, Thomson S, Rieder M, Van Uum S, Koren G. An assessment of cortisol analysis in hair and its clinical applications. Forensic Sci Int. 2010;196(1-3):32-7.

108. Kirschbaum C, Tietze A, Skoluda N, Dettenborn L. Hair as a retrospective calendar of cortisol production-Increased cortisol incorporation into hair in the third trimester of pregnancy. Psychoneuroendocrinol. 2009;34(1):32-7.

109. Luo H, Hu X, Liu X, Ma X, Guo W, Qiu C, et al. Hair cortisol level as a biomarker for altered hypothalamic-pituitary-adrenal activity in female adolescents with posttraumatic stress disorder after the 2008 Wenchuan earthquake. Biological Psychiatry. 2012;72(1):65-9.

110. Weaver ICG, Cervoni N, Champagne FA, D'Alessio AC, Sharma S, Seckl JR, et al. Epigenetic programming by maternal behavior. Nat Neurosci. 2004;7(8):847-54

111. McGowan PO, Sasaki A, CD'Alessio A, Dymov S, Labonté B, Szyf M, et al. Epigenetic regulation of the glucocorticoid receptor in human brain associates with childhood abuse. Nat Neurosci. 2009;12(3):342.

112. Paquette AG, Lester BM, Koestler DC, Lesseur C, Armstrong DA, Marsit CJ. Placental FKBP5 genetic and epigenetic variation is associated with infant neurobehavioral outcomes in the RICHS Cohort. PLOS ONE. 2014;9(8):e104913.

113. Klengel T, Mehta D, Anacker C, Rex-Haffner M, Pruessner JC, Pariante CM et al. Allele-specific FKBP5 DNA demethylation mediates gene-childhood trauma interactions. Nat Neurosci. 2013;16(1):33-41.

114. Bagot RC, Meaney MJ. Epigenetics and the biological basis of gene $x$ environment interactions. J Am Acad Child Adol Psychiatry. 2010;49(8):752-71.

115. Holsboer F, Ising M. Stress hormone regulation: Biological role and translation into therapy. Annu Rev Psychol. 2010;61(1):81-109.

116. Yehuda R, Flory J, Pratchett L, Buxbaum J, Ising M, Holsboer F. Putative biological mechanisms for the association between early life adversity and the subsequent development of PTSD. Psychopharmacology. 2010;1-13.

117. Simon VA, Feiring C, Kobielski McElroy S. Making Meaning of Traumatic Events: Youthsâ $\mathfrak{\epsilon}^{\mathrm{TM}}$ Strategies for Processing Childhood Sexual Abuse are Associated With Psychosocial Adjustment. Child Maltreatment. 2010;15(3):229-41.

118. Stadelmann S, Perren S, von Wyl A, von Klitzing K. Associations between family relationships and symptoms/strengths at kindergarten age: what is the role of children's parental representations? J Child Psychol Psychiatry. 2007:48(10):996-1004.

119. White LO, Wu J, Borelli JL, Mayes LC, Crowley MJ. Play it again: Neural responses to reunion with excluders predicted by attachment patterns. Developmental Science. 2013;16(6):850-63.

120. White LO, Wu J, Borelli JL, Rutherford HJV, David DH, Kim-Cohen J, et al. Attachment dismissal predicts frontal slow-wave ERPs during rejection by unfamiliar peers. Emotion. 2012;12(4):690-700.

121. Stadelmann S, Perren S, Groeben M, von Klitzing K. Parental Separation and Children's Behavioral/Emotional Problems: The Impact of Parental Representations and Family Conflict. Family Process. 2010;49(1):92-108.

122. von Klitzing K, Kelsay K, Emde R, Robinson J, Schmitz S. Gender-specific characteristics of 5-year-olds' play narratives and associations with behavior ratings. J Am Acad Child Adol Psychiatry. 2000;39(8):1017-23.
123. von Klitzing K, Stadelmann S, Perren S. Story stem narratives of clinical and normal kindergarten children: Are content and performance associated with children's social competence? Attachment Human Dev. 2007;9:271-86.

124. Groeben M, Perren S, Stadelmann S, von Klitzing K. Emotional symptoms from kindergarten to middle childhood: associations with self-and other-oriented social skills. Eur Child Adolesc Psychiatr. 2011;20(1):3-15.

125. Warren SL, Emde RN, Sroufe LA. Internal representations: Predicting anxiety from children's play narratives. J Am Acad Child Adol Psychiatry. 2000;39(1):100-7.

126. Belden AC, Sullivan JP, Luby JL. Depressed and healthy preschoolers' internal representations of their mothers' caregiving: Associations with observed caregiving behaviors one year later. Attachment Human Dev. 2007:9:239-54.

127. Toth SL, Cicchetti D, Macfie J, Emde RN. Representations of self and other in the narratives of neglected, physically abused, and sexually abused preschoolers. Dev Psychopath. 1997;9:781-96.

128. Toth SL, Cicchetti D, MacFie J, Maughan A, Vanmeenen K. Narrative representations of caregivers and self in maltreated pre-schoolers. Attachment Human Dev. 2000;2:271-305.

129. Grych J, Wachsmuth-Schlaefer T, Klockow L. Interparental aggression and young children's representations of family relationships. J Fam Psychol. 2002;16(3):259-72.

130. Stronach EP, Toth SL, Rogosch F, Oshri A, Todd Manly J, Cicchetti D. Child maltreatment, attachment security, and internal representations of mother and mother-child relationships. Child Maltreatment. 2011. doi:10.1177/ 1077559511398294

131. Macfie J, Cicchetti D, Toth SL. The development of dissociation in maltreated preschool-aged children. Dev Psychopath. 2001;13(02):233-54.

132. Macfie J, Toth SL, Rogosch FA, Robinson J, Emde RN, Cicchetti D. Effect of maltreatment on preschoolers' narrative representations of responses to relieve distress and of role reversal. Dev Psychol. 1999;35(2):460-5.

133. Shields A, Ryan R, Cicchetti D. Narrative representations of caregivers and emotion dysregulation as predictors of maltreated children's rejection by peers. Dev Psychol. 2001;37(3):321-37.

134. Toth SL, Cicchetti D, Macfie J, Rogosch FA, Maughan A. Narrative representations of moral-affiliative and conflictual themes and behavioral problems in maltreated preschoolers. J Clin Child Psychol. 2000;29(3):307-18.

135. Perren S, von Wyl A, Stadelmann S, Bürgin D, von Klitzing K. Associations between kindergarten children's behavioral/emotional difficulties and the quality of their peer relationships. J Am Acad Child Adol Psychiatry. 2006;45:867-76

136. Kraemer HC, Measelle JR, Ablow JC, Essex M, Boyce WT, Kupfer D. A new approach to integrating data from multiple informants in psychiatric assessment and research: Mixing and matching contexts and perspectives. Am J Psychiatry. 2003;160(9):1566-77.

137. Measelle JR, Ablow JC, Cowan PA, Cowan CP. Assessing young children's views of their academic, social, and emotional lives: An evaluation of the self-perception scales of the Berkeley Puppet Interview. Child Dev. 1998;69(6):1556-76.

138. von Klitzing K, White LO, Otto Y, Fuchs S, Egger HL, Klein AM. Depressive comorbidity in preschool anxiety disorder. J Child Psychol Psychiatry. 2014;55(10):1107-16

139. Brodsky BS, Oquendo M, Ellis SP, Haas GL, Malone KM, Mann JJ. The relationship of childhood abuse to impulsivity and suicidal behavior in adults with major depression. Am J Psychiatry. 2001;158(11):1871-7.

140. Chu JA, Dill DL. Dissociative symptoms in relation to childhood physical and sexual abuse. Am J Psychiatry. 1990;147(7):887-92.

141. Cicchetti D, Valentino K. An ecological-transactional perspective on child maltreatment: Failure of the average expectable environment and its influence on child development. In: Cicchetti D, Cohen DJ, editors. Developmental psychopathology. Volume 3: Risk, Disorder, and Adaptation. New York: Wiley; 2006. p. 129-201.

142. Manly JT. Advances in research definitions of child maltreatment. Child Abuse Neglect. 2005;29(5):425.

143. Barnett D, Manly J, Cicchetti D. Defining child maltreatment: The interface between policy and research. In: Cicchetti D, Toth SL, editors. Child abuse, child development, and social policy. Volume 8. New York: Ablex; 1993. p. 7-73.

144. Cicchetti D, Toth SL, Manly JT. Maternal Maltreatment Classification Interview. Rochester, NY: Mt. Hope Family Center, Univesity of Rochester; 2003.

145. Straus M, Hamby S, Finkelhor D, Moore D, Runyan D. Identification of child maltreatment with the Parent-child Conflict Tactics Scales: Development 
and psychometric data for a national sample of American parents. Child Abuse Neglect. 1998;22(4):249-70.

146. Kaufman Kantor G, Holt M, Mebert C, Straus MA, Drach K, Ricci L, et al. Development and preliminary psychometric properties of the multidimensional neglectful behavior scale-child report. Child Maltreatment. 2004;9(4):409.

147. Tagay S, Repic N, Düllmann S, Schlottbohm E, Hermans E, Hiller R, et al. Traumatische Ereignisse, psychische Belastung und Prädiktoren der PTBS-Symptomatik bei Kindern und Jugendlichen. Kindheit und Entwicklung 2013;22(2):70-9.

148. Tagay S, Düllmann S, Hermans E, Repic N, Hiller R, Senf W. Das Essener Trauma-Inventar für Kinder und Jugendliche (ETI-KJ). Zeitschrift für Kinder- und Jugendpsychiatrie und Psychotherapie. 2011;39(5):323-40,

149. Egger HL, Erkanli A, Keeler G, Potts E, Walter BK, Angold A. Test-retest reliability of the Preschool Age Psychiatric Assessment (PAPA). J Am Acad Child Adol Psychiatry. 2006;45(5):538.

150. Egger HL, Angold A. The Preschool Age Psychiatric Assessment (PAPA): A structured parent interview for diagnosing psychiatric disorders in preschool children. In: Delcarmen-Wiggins R, Carter A, editors. Handbook of infant, toddler, and preschool mental health assessment. New York: Oxford University Press; 2004. p. 223-43.

151. Goodman R. The Strengths and Difficulties Questionnaire: A Research Note. J Child Psychol Psychiatry. 1997;38(5):581-6.

152. Achenbach TM. Manual for the Child Behavior Checklist 4-18 and 1991 Profile. Burlington, VT: University of Vermont; 1991.

153. Klein AM, Otto Y, Fuchs S, Zenger M, von Klitzing K. Psychometric properties of the parent-rated SDQ in preschoolers. Eur J Psychol Assess. 2013;29(2):96-104.

154. Woerner W, Becker A, Rothenberger A. Normative data and scale properties of the German parent SDQ. Eur Child Adolesc Psychiatr. 2004;13.

155. Weissman MM, Orvaschel H, Padian N. Children's symptom and social functioning self-report scales comparison of mothers' and children's reports. J Nerv Ment Dis. 1980;168(12):736-40.

156. Birmaher B, Brent DA, Chiappetta L, Bridge J, Monga S, Baugher M. Psychometric properties of the Screen for Child Anxiety Related Emotional Disorders (SCARED): A replication study. J Am Acad Child Adol Psychiatry. 1999;38(10):1230-6.

157. Achenbach TM, Edelbrock C. Manual for the youth self-report and profile: University of Vermont, Burlington, VT: Department of Psychiatry; 1989.

158. Ivanova MY, Achenbach TM, Rescorla LA, Dumenci L, Almqvist F, Bilenberg $\mathrm{N}$, et al. The generalizability of the Youth Self-Report syndrome structure in 23 societies. J Consulting Clin Psychol. 2007;75(5):729.

159. Frühe B, Allgaier A-K, Pietsch K, Baethmann M, Peters J, Kellnar S, et al. Children's Depression Screener (ChilD-S): Development and Validation of a Depression Screening Instrument for Children in Pediatric Care. Child Psychiatr Hum Dev. 2012;43(1):137-51.

160. Ablow JC, Measelle JR. The Berkeley Puppet Interview: Interviewing \& Coding System Manuals. In: Eugene, OR: University of Oregon; 1993.

161. Measelle JR, John OP, Ablow JC, Cowan PA, Cowan CP. Can children provide coherent, stable, and valid self-reports on the big five dimensions? A longitudinal study from ages 5 to 7. J Pers Soc Psychol. 2005;89(1):90-106.

162. Kaufman J, Birmaher B, Brent D, Rao U, Flynn C, Moreci $P$, et al. Schedule for Affective Disorders and Schizophrenia for School-Age Children-Present and Lifetime Version (K-SADS-PL): Initial reliability and validity data. J Am Acad Child Adol Psychiatry. 1997;36(7):980-8.

163. Eisenberg N, Fabes RA, Guthrie IK, Murphy BC, Maszk P, Holmgren R, et al. The relations of regulation and emotionality to problem behavior in elementary school children. Dev Psychopath. 1996;8(1):141-62.

164. Hill J, Murray L, Leidecker $V$, Sharp $H$. The dynamics of threat, fear and intentionality in the conduct disorders: longitudinal findings in the children of women with post-natal depression. Philos Trans R Soc London Ser B. 2008;363(1503):2529-41.

165. Kistner J. Children's peer acceptance, perceived acceptance, and risk for depression. In: Joiner Jr T, Brown E, Kistner J, editors. The interpersonal, cognitive, and social nature of depression. Mahwah, NJ: Lawrence Erlbaum; 2006. p. 1-21.

166. Essau CA, Sasagawa S, Frick PJ. Callous-unemotional traits in a community sample of adolescents. Assessment. 2006;13(4):454-69.

167. Frick PJ. The Inventory of Callous-Unemotional Traits. New Orleans, LA: University of New Orleans; 2003.

168. Bretherton I, Oppenheim D. The MacArthur Story Stem Battery: development, administration, reliability, validity, and reflections about meaning. In: Emde RN, Wolf DP, Oppenheim D, editors. Revealing the inner worlds of young children: The MacArthur Story Stem Battery and parent-child narratives. Oxford: Oxford University Press; 2003. p. 55-80.

169. Robinson JL, Mantz-Simmons L, Macfie J, Kelsay K, The MacArthur Narrative Group. MacArthur Narrative Coding Manual. In. Topeka, KS: Unpublished document, Menninger Clinic; 2002.

170. Hill J, Sharp H, Hoover D, Taliaferro G, Fonagy P, Leidecker V. Rating Scales for the MSSB and the Reading Doll's House Task: MSSB Version. In Denver, CO: Unpublished document, University of Colorado Health, Sciences Center; 2009.

171. Schulz U, Schwarzer R. Social support in coping with illness: the Berlin Social Support Scales (BSSS). Diagnostica. 2003;49(2):73-82.

172. Barrera M. A method for the assessment of social support networks in community survey research. Connections. 1980;3(3):8-13.

173. Kaufman J. Depressive disorders in maltreated children. J Am Acad Child Adol Psychiatry. 1991;30(2):257-65.

174. Kaufman J, Yang BZ, Douglas-Palumberi H, Grasso D, Lipschitz D, Houshyar $S$, et al. Brain-derived neurotrophic factor-5-HTTLPR gene interactions and environmental modifiers of depression in children. Biol Psychiatr. 2006;59(8):673-80.

175. Winkler J, Stolzenberg H. Der Sozialschichtindex im Bundes-Gesundheitssurvey [Social class index in the Federal Health Survey]. Gesundheitswesen. 1999;61(2):178-83.

176. Rutter M, Quinton D. Psychiatric disorder: ecological factors and concepts of causation. In: McGurk H, editor. Ecological factors in human development. Amsterdam: North-Holland; 1977. p. 173-87.

177. Franiek S, Reichle B. Elterliches Erziehungsverhalten und Sozialverhalten im Grundschulalter. Kindheit und Entwicklung. 2007;16(4):240-9.

178. Frick PJ. The Alabama Parenting Questionnaire. In: Unpublished rating scale. Tuscaloosa, AL: University of Alabama; 1991.

179. Engfer A, Schneewind KA. Causes and consequences of harsh parental punishment : An empirical investigation in a representative sample of 570 German families. Child Abuse Neglect. 1982;6(2):129-39.

180. Moos RH, Moos BS. Manual for the family environment scale, vol. 50. Palo Alto, CA: Consulting Psychologists Press; 1981.

181. Wennig R. Potential problems with the interpretation of hair analysis results. Forensic Sci Int. 2000;107(1-3):5-12.

182. Stalder T, Steudte S, Miller R, Skoluda N, Dettenborn L, Kirschbaum C. Intraindividual stability of hair cortisol concentrations. Psychoneuroendocrinol. 2012;37(5):602-10.

183. Accorsi PA, Carloni E, Valsecchi P, Viggiani R, Gamberoni M, Tamanini C, et al. Cortisol determination in hair and faeces from domestic cats and dogs. Gen Comp Endocrinol. 2008;155(2):398-402.

184. Davenport MD, Tiefenbacher S, Lutz CK, Novak MA, Meyer JS. Analysis of endogenous cortisol concentrations in the hair of rhesus macaques. Gen Comp Endocrinol. 2006;147(3):255-61.

185. Manenschijn L, Koper JW, Lamberts SWJ, van Rossum EFC. Evaluation of a method to measure long term cortisol levels. Steroids. 2011;76:1032-6.

186. Parrott A, Sands H, Jones L, Clow A, Evans P, Downey L, et al. Increased cortisol levels in hair of recent Ecstasy/MDMA users. Eur Neuropsychopharmacol. 2014;24(3):369-74.

187. Stalder T, Kirschbaum C, Heinze K, Steudte S, Foley P, Tietze A, et al. Use of hair cortisol analysis to detect hypercortisolism during active drinking phases in alcohol-dependent individuals. Biological Psychology. 2010;85(3):357-60.

188. Thomson S, Koren G, Fraser LA, Rieder M, Friedman TC, Van Uum SHM. Hair analysis provides a historical record of cortisol levels in cushing's syndrome. Exp Clin Endocrinol Diabetes. 2010;118(2):133-8.

189. Fairbanks LA, Jorgensen MJ, Bailey JN, Breidenthal SE, Grzywa R, Laudenslager ML. Heritability and genetic correlation of hair cortisol in vervet monkeys in low and higher stress environments. Psychoneuroendocrinol. 2011;26(8):1201-8.

190. Dettenborn L, Tietze A, Bruckner F, Kirschbaum C. Higher cortisol content in hair among long-term unemployed individuals compared to controls. Psychoneuroendocrinol. 2010;35(9):1404-9.

191. Karlen J, Ludvigsson J, Frostell A, Theodorsson E, Faresjo T. Cortisol in hair measured in young adults - a biomarker of major life stressors? BMC Clin Pathol. 2011;11(1):12

192. Stalder T, Tietze A, Steudte S, Alexander N, Dettenborn L, Kirschbaum C. Elevated hair cortisol levels in chronically stressed dementia caregivers. Psychoneuroendocrinol. 2014;47:26-30. 
193. Manenschijn L, Schaap L, van Schoor NM, van der Pas S, Peeters GMEE, Lips P, et al. High Long-Term Cortisol Levels, Measured in Scalp Hair, Are Associated With a History of Cardiovascular Disease. J Clin Endocrinol Metab. 2013;98(5):2078-83.

194. Pereg D, Gow R, Mosseri M, Lishner M, Rieder M, Van Uum S, et al. Hair cortisol and the risk for acute myocardial infarction in adult men. Stress. 2011;14(1):73-81.

195. Stalder T, Kirschbaum C, Alexander N, Bornstein SR, Gao W, Miller R, et al. Cortisol in hair and the metabolic syndrome. J Clin Endocrinol Metab. 2013;98(6):2573-80.

196. Dowlati Y, Herrmann N, Swardfager W, Thomson S, Oh PI, Van Uum S, et al. Relationship between hair cortisol concentrations and depressive symptoms in patients with coronary artery disease. Neuropsychiatr Dis Treat. 2010;6:393-400.

197. Raul J-S, Cirimele V, Ludes B, Kintz P. Detection of physiological concentrations of cortisol and cortisone in human hair. Clinical Biochemistry. 2004;37(12):1105-11.

198. Sauvé B, Koren G, Walsh G, Tokmakejian S, Van Uum SH. Measurement of cortisol in human hair as a biomarker of systemic exposure. Clin Invest Med. 2007;30(5):E183-91.

199. Stalder T, Kirschbaum C. Analysis of cortisol in hair - State of the art and future directions. Brain Behav Immun. 2012;26(7):1019-29.

200. Feller S, Vigl M, Bergmann MM, Boeing H, Kirschbaum C, Stalder T. Predictors of hair cortisol concentrations in older adults. Psychoneuroendocrinol. 2014;39:132-40.

201. Manenschijn L, van Kruysbergen RG, de Jong FH, Koper JW, van Rossum EF. Shift work at young age is associated with elevated long-term cortisol levels and body mass index. J Clin Endocrinol Metab. 2011;96(11):E1862-5.

202. Foley P, Kirschbaum C. Human hypothalamus-pituitary-adrenal axis responses to acute psychosocial stress in laboratory settings. Neurosci Biobehav Rev. 2010;35(1):91-6.

203. Kirschbaum C, Pirke KM, Hellhammer DH. The 'Trier Social Stress Test'—a tool for investigating psychobiological stress responses in a laboratory setting. Neuropsychobiology. 1993;28(1-2):76-81.

204. Buske-Kirschbaum A, Jobst S, Wustmans A, Kirschbaum C, Rauh W, Hellhammer D. Attenuated free cortisol response to psychosocial stress in children with atopic dermatitis. Psychosom Med. 1997;59(4):419-26.

205. Dickerson S, Kemeny M. Acute Stressors and Cortisol Responses: A Theoretical Integration and Synthesis of Laboratory Research. Psychol Bull. 2004;130(3):36

206. Nater UM, Rohleder N. Salivary alpha-amylase as a non-invasive biomarker for the sympathetic nervous system: Current state of research. Psychoneuroendocrinol. 2009;34(4):486-96.

207. Greaves RF, Jevalikar G, Hewitt JK, Zacharin MR. A guide to understanding the steroid pathway: New insights and diagnostic implications. Clin Biochem. 2014;47(15):5-15.

208. Raven JC. Standard progressives matrices. London: H.K. Lewis; 1958.

209. Raven JC. Manual for the Coloured Progressive Matrices (Revised). Windsor, UK: NFER-Nelson; 1984.

210. Weiss R, Albinus B. Grundintelligenztest Skala 2-Revision (CFT 20-R): Braunschweig, Germany: Hogrefe; 2006

211. Elben CE, Lohaus A. Marburger Sprachverständnistest für Kinder: Göttingen, Germany: MSVK: Hogrefe, Verlag für Psychologie; 2000.

212. Dunn LM, Dunn LM. Peabody Picture Vocabulary Test: Forms $L$ and $M$ : Circle Pines, MN: American Guidance Service; 1981.

213. Lenhard A, Lenhard W, Segerer R, Suggate S. Peabody Picture Vocabulary Test - Revision IV (Deutsche Adaption). Frankfurt a. M., Germany: Pearson Assessment $\mathrm{GmbH}$; in press.

214. Cicchetti D, Lynch M. Toward an ecological/transactional model of community violence and child maltreatment: consequences for children's development. Psychiatry. 1993;56(1):96-118.

215. Kraemer HC, Stice E, Kazdin A, Offord D, Kupfer D. How do risk factors work together? Mediators, moderators, and independent, overlapping, and proxy risk factors. Am J Psychiatry. 2001;158(6):848-56.

216. Rutter M. Psychosocial resilience and protective mechanisms. Am J Orthopsychiatry. 1987;57(3):316-31.
217. Rutter M, Kim-Cohen J, Maughan B. Continuities and discontinuities in psychopathology between childhood and adult life. J Child Psychol Psychiatry. 2006;47(3 4):276-95.

218. Janzing D, Schoelkopf B. Causal inference using the Algorithmic Markov Condition. IEEE Trans Information Theory. 2010;56:5168-94.

219. Masten AS, Best KM, Garmezy N. Resilience and development: Contributions from the study of children who overcome adversity. Dev Psychopath. 1990:2(4):425-44

\section{Submit your next manuscript to BioMed Central and take full advantage of:}

- Convenient online submission

- Thorough peer review

- No space constraints or color figure charges

- Immediate publication on acceptance

- Inclusion in PubMed, CAS, Scopus and Google Scholar

- Research which is freely available for redistribution 